\title{
Magic Curiosity Arousing Tricks (MagicCATs): a novel stimulus collection to induce epistemic emotions
}

Article

Published Version

Creative Commons: Attribution 4.0 (CC-BY)

Open Access

Ozono, H., Komiya, A., Kuratomi, K., Hatano, A., Fastrich, G., Raw, J. A. L., Haffey, A., Meliss, S., Lau, J. K. L. and Murayama, K. (2021) Magic Curiosity Arousing Tricks (MagicCATs): a novel stimulus collection to induce epistemic emotions. Behavior Research Methods, 53 (1). pp. 188-215. ISSN 1554-351X doi: https://doi.org/10.3758/s13428-02001431-2 Available at https://centaur.reading.ac.uk/91324/

It is advisable to refer to the publisher's version if you intend to cite from the work. See Guidance on citing.

To link to this article DOI: http://dx.doi.org/10.3758/s13428-020-01431-2

Publisher: Springer

All outputs in CentAUR are protected by Intellectual Property Rights law, including copyright law. Copyright and IPR is retained by the creators or other copyright holders. Terms and conditions for use of this material are defined in the End User Agreement. 


\section{CentAUR}

Central Archive at the University of Reading

Reading's research outputs online 


\title{
Magic Curiosity Arousing Tricks (MagicCATs): A novel stimulus collection to induce epistemic emotions
}

\author{
Hiroki Ozono ${ }^{1}$ (D) Asuka Komiya ${ }^{2} \cdot$ Kei Kuratomi $^{3} \cdot$ Aya Hatano $^{4}$. Greta Fastrich ${ }^{6}$ - Jasmine April Louise Raw ${ }^{7}$. \\ Anthony Haffey ${ }^{7} \cdot$ Stefanie Meliss ${ }^{7} \cdot$ Johnny King L. Lau ${ }^{7} \cdot$ Kou Murayama ${ }^{5,7}$
}

(C) The Author(s) 2020

\begin{abstract}
There has been considerable interest in empirical research on epistemic emotions, i.e., emotions related to knowledge-generating qualities of cognitive tasks and activities such as curiosity, interest, and surprise. One big challenge when studying epistemic emotions is systematically inducting these emotions in restricted experimental settings. The current study created a novel stimulus set called Magic Curiosity Arousing Tricks (MagicCATs): a collection of 166 short magic trick video clips that aim to induce a variety of epistemic emotions. MagicCATs are freely available for research and can be used in a variety of ways to examine epistemic emotions. Rating data also support that the magic tricks elicit a variety of epistemic emotions with sufficient inter-stimulus variability, demonstrating good psychometric properties for their use in psychological experiments.
\end{abstract}

Keywords intrinsic motivation $\cdot$ epistemic emotions $\cdot$ curiosity $\cdot$ science of magic

Recent years have seen a surge of interest in the topic of socalled epistemic emotions. Epistemic emotions refer to a group of emotions which are related to the knowledgegenerating qualities of cognitive tasks and activities (Brun, Doğuoğlu, \& Kuenzle, 2008; Muis, Chevrier, \& Singh, 2018). These emotions typically include surprise, curiosity and interest. Recent studies have revealed that these epistemic emotions have profound implications for cognitive processing

Hiroki Ozono

hiroki.ozono@gmail.com

$\triangle$ Kou Murayama

k.murayama@reading.ac.uk

1 Faculty of Law, Economics and Humanities, Kagoshima University, Korimoto, Kagoshima 890-0065, Japan

2 Graduate School of Humanities and Social Sciences, Hiroshima University, Higashi-Hiroshima, Japan

3 Faculty of Psychology, Aichi Shukutoku University, Nagakute, Japan

4 Department of Cognitive Psychology in Education, Graduate School of Education, Kyoto University, Kyoto, Japan

5 Research Institute, Kochi University of Technology, Kochi, Japan

6 School of Psychology, University of Western Australia, Perth, Australia

7 School of Psychology and Clinical Language Sciences, University of Reading, Earley Gate, Whiteknights, Reading RG6 6AL, UK and learning. Surprise is caused by the discrepancy between expected and actual outcomes, and this discrepancy (which can be described as 'prediction error') is the basis of learning and decision-making (Dole \& Sinatra, 1998; Rescorla \& Wagner, 1972). Stahl and Feigenson (2015) showed that even 11-month-old infants can learn from events better when their expectation was violated (i.e., they were surprised). A number of recent studies have also found that the strength of the feeling of curiosity or interest triggered by the presentation of trivia questions predicts memory accuracy of the answers to the questions (Fastrich, Kerr, Castel, \& Murayama, 2017; Kang et al., 2009; Marvin \& Shohamy, 2016; McGillivray, Murayama, \& Castel, 2015; Wade \& Kidd, 2019) as well as that of irrelevant materials that were incidentally presented (Galli et al., 2018; Gruber, Gelman, \& Ranganath, 2014).

One of the challenges of research on epistemic emotions is that it is not easy to induce these epistemic emotions in experimental settings. In controlled experiments, including those with neuroscientific facilities such as functional magnetic resonance imaging (fMRI), researchers need a number of short repeated trials to ensure the reliability of the task. However, triggering epistemic emotions in such a short time frame is challenging because epistemic emotions, by definition, require people to cognitively process the task; epistemic emotions are not something that can be immediately triggered upon presenting a stimulus. In addition, even if it is possible to induce epistemic emotions in a short time frame, the 
magnitude of the emotion is likely to be insufficient to cause a psychological response and/or behavioral change. Thus, there are limited experimental materials that claim to induce epistemic emotions. In fact, the vast majority of studies in experimental psychology use trivia questions or similar knowledge questions to induce epistemic emotions, particularly curiosity (Baranes, Oudeyer, \& Gottlieb, 2015; Kang et al., 2009; Litman, Hutchins, \& Russon, 2005; Metcalfe, Schwartz, \& Bloom, 2017; Murayama \& Kuhbandner, 2011) ${ }^{1}$.

In the current study, we have validated a stimulus set called Magic Curiosity Arousing Tricks (MagicCATs): a collection of 166 novel short magic trick video clips that trigger people's epistemic emotions in experimental settings. The videos of MagicCATs are available for researchers (see "Stimulus Availability" section in Methods) and the current article reports basic characteristics and the norms of these magic trick video clips. There are already several studies that have used magic tricks as stimuli to trigger epistemic emotions, including neuroimaging studies (e.g., Parris, Kuhn, Mizon, Benattayallah, \& Hodgson, 2009, Danek, Öllinger, Fraps, Grothe, \& Flanagin, 2015), but to the best of our knowledge, there are no standardized stimuli that are freely available to researchers. In contrast to other materials, one unique aspect of magic tricks is that they induce a strong sense of violation of expectation and surprise (Danek et al., 2015). Surprise and curiosity/interest are obviously interrelated epistemic emotions (Pekrun, Vogl, Muis, \& Sinatra, 2017), but the materials available thus far (e.g., trivia questions) are not designed to induce surprise to evoke curiosity (for an exception, see Vogl, Pekrun, Murayama, \& Loderer, 2019; Vogl, Pekrun, Murayama, Loderer, \& Schubert, 2019). Perhaps as a consequence of this curiosity research tends to focus on uncertainty as a major triggering factor (e.g., van Lieshout, Vandenbroucke, Müller, Cools, \& de Lange, 2018), and the role of surprise in relation to curiosity and interest has been relatively under-examined.

Another important feature of magic tricks is their relatively strong, intuitive, and universal appeal. Because magic tricks are intended to create a strong violation of expectation, spectators are naturally motivated to understand why the expectation is violated ("why did this happen?"), which is thus likely to induce relatively strong feelings of epistemic emotions. An advantage of magic tricks is that they mainly consist of nonverbal information such as vanishing or appearing materials. This nonverbal nature of the stimuli makes it easier for people to intuitively understand the content. As a result, magic tricks can trigger epistemic emotions regardless of the participant's language, educational and cultural backgrounds. Of course, we are not claiming that magic tricks are superior to existing

\footnotetext{
${ }^{1}$ A limited number of studies used different materials to elicit epistemic emotions such as blurred pictures (Jepma, Verdonschot, van Steenbergen, Rombouts, \& Nieuwenhuis, 2012), visual arts (Silvia, 2005), and philosophical quotations (Fayn, Silvia, Dejonckheere, Verdonck, \& Kuppens, 2019).
}

stimuli to trigger epistemic emotions. There are some obvious limitations such as difficulties controlling stimulus length. However, given the unique advantages of magic tricks, we believe that the current stimulus set provides complementary benefits to the researchers studying epistemic emotions.

There are different ways to utilize MagicCATs in research, but one common context is an experiment in which researchers intend to elicit different levels of epistemic emotions on a trial-by-trial basis to examine the within-person correlates of epistemic emotions. We have already conducted one neuroimaging experiment using MagicCATs and validated the effectiveness of the stimuli. In Lau, Ozono, Kuratomi, Komiya, \& Murayama (2020), we presented participants with a series of 36 magic trick video clips from MagicCATS to induce feeling of curiosity and asked them to decide whether they would be willing to risk receiving electric shocks to satisfy the curiosity to know the solution of the trick. Selfreported ratings of curiosity for each magic trick was significantly associated with the decision to accept the risk to receive electric shocks on a trial-by-trial basis, indicating that the magic trick videos successfully induced curiosity.

The collection of magic trick video clips we provide would also benefit the recent growing area called the "science of magic", which investigates human cognitive mechanisms using magic tricks (for review, see Kuhn, Amlani, Rensink, 2008; Kuhn, 2019; Thomas, Didierjean, Maquestiaux, \& Gygax, 2015). Broadly speaking, magic tricks can be classified by the three general methods used by magicians: misdirection, illusion and forcing (Kuhn et al., 2008). By embedding these types of magic tricks in psychological experiments, we can gain unique insight into cognitive processes. For example, the technique of misdirection, i.e., manipulating the spectator away from the cause of magic effect (Kuhn et al., 2008), is useful to investigate mechanisms of attention (e.g., Barnhart \& Goldinger, 2014; Kuhn \& Findlay, 2010; Kuhn \& Land, 2006; Wiseman \& Nakano, 2016). Also, many magic tricks are based on visual or cognitive illusions (e.g., Macknik, Martinez-Conde, \& Blakeslee, 2010). Investigating how magicians use such illusions in practice may lead to new insights in perception and cognition (Ekroll, Sayim, and Wagemans, 2013). Furthermore, some magic tricks force the spectators to choose a certain object while the spectators believe that they made the choice out of their free will. Investigating how and why spectators have such false beliefs can lead to better understanding of human free will and agency (Kuhn, Pailhès, \& Lan, 2020; Olson, Amlani, \& Rensink, 2013; Ozono, 2017; Pailhès, \& Kuhn, 2020). Our magic trick videos include misdirection, illusion, and forcing as well as other various trick mechanisms (e.g., tricks utilizing mathematical logic or physical principles), allowing researchers to pursue a variety of psychological research questions.

The current paper describes how we created MagicCATs, which aims to induce epistemic emotions in psychological experiments. We then provide rating data and perform 
quantitative analysis to examine the psychometric properties of MagicCATs. Specifically, we show that the magic tricks elicit a variety of epistemic emotions (surprise in response to the trick, interest in the trick, and curiosity in the solution) with sufficient inter-stimulus variability.

\section{Methods}

\section{Creating MagicCATs}

Four male magicians, including a champion of an international magic competition, performed 145 magic tricks in total. These performances were filmed in two studios (one studio for one magician and another studio for the other three magicians) by professional photographers using high resolution video cameras. The magicians selected magic tricks that would maximize the variety of materials (e.g., playing cards, coins, sponges etc.) and the types of the tricks (e.g., vanishing, transportation, prediction, etc.). Magicians also ensured that the magic tricks were heterogeneous enough to induce different levels of epistemic emotions (i.e., surprise, interest, and curiosity). As most previous research on curiosity and interest were comparing the responses to the stimuli that induce either a low or high-level of curiosity and interest (Fastrich et al., 2017; Gruber et al., 2014; Kang et al., 2009), it is important to have sufficient inter-stimulus variability (i.e., it is critical to include magic tricks that are relatively less surprising/interesting). See Appendix Table 6 for the details of the MagicCATs.

All videos were then edited using Adobe ${ }^{\circledR}$ Premiere Pro CC® (2015) software to have a similar monotonic (dark) background, size (720 x 404 pixels) and viewing focus. The videos were muted, and English subtitles were added in a few videos, when necessary. The face of the magician was obscured as much as possible to avoid potential distraction due to their appearance and facial expressions. This editing also helps minimize potential responses to the gender of the magicians reported by Gygax, Thomas, Didierjean, \& Kuhn (2019). Twenty-one magic tricks out of the 145 tricks were relatively long and included a sequence of more than one tricks. For these videos, we created a short-version focusing on the first trick that was presented, in addition to the original long version, thus giving researchers more flexibility in stimulus selection (e.g., choosing stimuli that fit within a specific time constraint). In total, we created 166 video clips including the 21 long video clips of tricks that are accompanied by 21 short versions and 124 other videos. These videos ranged between 8 and $155 \mathrm{~s}$ long $($ mean $=37.3$; median $=31$; $\mathrm{SD}=$ 23.5). Without including the long versions, the videos raged between 8 and $105 \mathrm{~s}$ long $($ mean $=33.1$; median $=30$; $\mathrm{SD}=$ 19.8) . Here are the URLs of three video samples. https:// youtu.be/aVM-7VlXE5k, https://youtu.be/BAJ25HmsF-I, https://youtu.be/ehgSKYxVL3M

\section{Rating task}

Participants A total of 495 participants took part in the rating task through Amazon Mechanical Turk. A total of 470 US participants were paid $\$ 3.5$ for approximately $35 \mathrm{~min}$ of study participation, whist the first 25 participants were paid $\$ 2.5$ before our re-calculation of the more realistic study completion time. Prior to the main data analysis, we excluded 44 participants who either (a) took more than +2 SD longer than average to complete the experiment (there is no participant who took shorter than 2SD below the average duration); (b) gave identical ratings on more than three questions for all trials; (c) answered "no" to the "clarity of the trick" question for all the presented video clips (see below); (d) indicated some issues in video presentation and internet connection in post-questions; or (e) indicated that they were distracted during the experiment or had already taken part in a similar experiment previously. This exclusion led to the final sample of 451 participants; 259 males and 192 females (mean age = $36.10, \mathrm{SD}=10.34$, range $=20-71$ ).

Stimulus lists It was impractical for any single participant to view and rate all the 166 video clips in MagicCATs, particularly as there were some duplicated magic tricks due to the short- and long-version as described above. To address this, we split the 166 video clips into nine lists and only presented each participant video clips from two of the lists. Our design is an adopted version of a Balanced Incomplete Block (BIB) spiraling procedure in the literature of test theory (Fleiss, 1981; Hanani, 1961).

The nine lists (Lists 1-9) were created in the following manner. Lists 1 and 2 consisted of 21 tricks from the short and long versions of the video clips mentioned earlier. Short and long versions of the video clips were assigned evenly to these lists (i.e., List 1 included ten short- and 11 long-version video clips; List 2 included 11 short- and ten long-version video clips). Video clips from the same magic trick were not assigned to the same list, thus when List 1 included a short version of a magic trick, List 2 included a long version of the same magic trick. The other 124 video clips were assigned to the remaining 7 lists (List 3 to List 9), resulting in 17 or 18 video clips for each of the lists. When creating these lists, we attempted to minimize the difference in the total duration of the video clips between lists. Consequently, the total duration of the video clips in Lists 1 and 2 were 16-17 $\mathrm{min}$ and 910 min in Lists 3 to 9.

Procedure Participants were presented with video clips from two of the nine lists in a randomized order. The assignment of the lists was randomly determined with the constraint that participants were not presented both Lists 1 and 2 because they included video clips from the same magic tricks but of different lengths. For each video clip participants gave five 
different ratings: (a) whether they understood the intention of the magic trick or not (clarity of the trick); (b) how surprised they were at the magic trick (surprise in response to the trick); (c) how interesting the magic tricks were (interest in the trick); (d) how confident they were that they had figured out the solution to the trick (confidence in the solution); and (e) how curious they were about how the magic trick was done (curiosity of the solution). Clarity of the trick, which assessed whether participants understand what happened after seeing the video clip, was rated using a binary response scale (Yes/ No); we included this rating to be used as an exclusion criterion. The other four questions were rated on 10-point Likert scales ranging from 1 (not at all) to 10 (very much).

At the end of the session, participants gave some postexperiment ratings. First, participants reported how much they were interested in the magic tricks in general ( 1 being not at all and 10 being very much) and whether they perform magic tricks themselves ( 1 being not at all, 2 being a little bit and 3 being frequently). Second, they reported any video presentation or internet connection problems that had occurred during the experiment; whether they were doing anything else during the experiment and whether they had already participated in another experiment with the same videos. We emphasized that their compensation would not be affected by their responses. As indicated above, these questions were used to exclude participants from the main data analysis who seemed to have been disengaged during the study.

\section{Results}

Analysis on the post hoc questions showed that participants were generally interested in the magic tricks $\mathrm{M}=7.13, \mathrm{SD}=$ 2.05. Only six participants indicated that they frequently performed magic tricks; 379 participants indicated that they had never performed a magic trick. In the following, we did not use the data for Trick 9 because it mistakenly contained sounds (we still include this magic trick in the final stimulus set in Appendix Table 6).

Table 1 reports the descriptive statistics of the main variables (clarity of the trick, surprise in response to the trick, interest in the trick, confidence in the solution, and curiosity in the solution) with video clips as the unit of analysis. On average, participants understood the intention of the magic tricks the majority of the time $(86.03 \%)$. When looking at the average proportion of participants who understood the magic trick for each video clip (Appendix Table 7), the majority of the video clips (156 out of the 165 video clips) were understood by more than $70 \%$ of participants. However, there were nine video clips that were understood by less than $70 \%$ of participants. In the following analysis, all the data of the trials in which the intentions of the magic tricks were unclear to participants were removed.
Participants reported a moderate level of surprise in response to the trick, interest in the trick, and curiosity in the solution $(\mathrm{M}=5.58,5.70$, and $5.71, \mathrm{SD}=0.81,0.77,0.72$, respectively, on a $1-10$ scale). These average rating values were consistent with the fact that we intended to include both surprising and less surprising magic tricks to ensure the heterogeneity of the stimulus set. The average confidence in the solution is relatively low $(M=4.14)$. Note that this is a subjective rating of confidence and we do not have objective data to demonstrate that participants indeed correctly guessed the solution behind some of the magic tricks.

To further examine whether our new stimuli can appropriately evaluate within-person variability of epistemic emotions, we applied a mixed-effects model to the data to decompose the three distinct variance components: participant variance, video variance, and participant $x$ video variance. Participant variance represents overall individual differences between participants (i.e., some participants had relatively high experience of surprise compared to others across all of the video clips), whereas video variance represents differences in ratings between video clips (e.g., some video clips are more surprising than other video clips to all participants). Participant $\mathrm{x}$ video variance represents individual differences in participants' responses to different video clips (e.g., some participants were interested in a specific video clip whereas others were not). Note that participant $\mathrm{x}$ video variance also includes variance from measurement errors, which we cannot statistically separate. In most of the previous literature on epistemic emotions (e.g., Fayn et al., 2019; Fastrich et al., 2017; Vogl et al. 2019, 2019), withinperson variability reflected both the stimulus variance and participant $x$ stimulus variance (i.e., video variance and participant $\mathrm{x}$ video variance in this study).

The mixed model regression found that the majority of the variance can be explained by the participant $\mathrm{x}$ video clip for all the ratings (Table 2). The random effect of participant variance explains about $36-43 \%$ of the response variance. The random effect of video is the smallest, explaining about 5$7 \%$ of the variance. These results indicate that these materials have sufficient within-person variability (57-64\%) to examine intra-individual fluctuation of these epistemic emotions. The findings are also largely consistent with the findings of Fastrich et al. (2017) who used trivia questions.

One limitation of the variance decomposition analysis in Table 2 is that we cannot dissociate the participant $\mathrm{x}$ video variance from measurement error variance; it is possible that within-person variance that we reported is an overestimation. Although it is difficult to perfectly address the issue, to gain more insights into the rating data we conducted further mixedeffects modeling to further decompose the variance by treating ratings of epistemic emotions as an additional factor. More specifically, we regarded the data as three mode data of participant $\mathrm{x}$ videos $\mathrm{x}$ type of epistemic emotions (emotion type being either surprise in response to the trick, interest in the trick or curiosity 
Table 1 Descriptive statistics for the 166 magic trick videos

\begin{tabular}{llllll}
\hline & $\begin{array}{l}\text { Clarity } \\
\text { of the } \\
\text { trick }\end{array}$ & $\begin{array}{l}\text { Surprise in } \\
\text { response to the } \\
\text { trick }\end{array}$ & $\begin{array}{l}\text { Interest } \\
\text { in the } \\
\text { trick }\end{array}$ & $\begin{array}{l}\text { Confidence } \\
\text { in the } \\
\text { solution }\end{array}$ & $\begin{array}{l}\text { Curiosity } \\
\text { in the } \\
\text { solution }\end{array}$ \\
\hline Mean & .86 & 5.58 & 5.70 & 4.14 & 5.71 \\
SD & .09 & 0.81 & 0.77 & 0.84 & 0.72 \\
Min & .47 & 3.86 & 3.95 & 2.54 & 3.87 \\
Max & .97 & 7.65 & 7.88 & 7.23 & 7.89 \\
\hline
\end{tabular}

Note: The rating scale ranged from 1 to 10 . We first computed the mean of each video clip (across participants) and then computed the descriptive statistics. Except for the clarity, we removed the trials that were unclear to participants.

in the solution), and conducted mixed-effects modeling to estimate the variance components of each factor and their interactions. We excluded confidence from the analysis because confidence was not assessed as an epistemic emotion. As emotion type variance was very small and caused a convergence error, we eliminated this term from the final model. Table 3 includes these results. Note that participant $\mathrm{x}$ video $\mathrm{x}$ emotion type variance is confounded with measurement error variance. One important finding from this analysis is that the large contribution of the participant $\mathrm{x}$ video clip observed in the original variance decomposition model (Table 2) is now largely absorbed into participant $\mathrm{x}$ video variance (not participant $\mathrm{x}$ video $\mathrm{x}$ emotion type variance), which is no longer confounded with error terms. This finding means that measurement error was not a major source of the participant $\mathrm{x}$ video clip variance observed in the original model. Another important observation is that emotion type explained a relatively small portion $(20.1 \%)$ of the total variance (Video $\mathrm{x}$ emotion type + Participant $\mathrm{x}$ emotion type + Participant $\mathrm{x}$ video $\mathrm{x}$ emotion type, which includes measurement errors). These results suggest the possibility that participants did not make a very strong distinction between the three types of epistemic emotions.

We also examined the extent to which these ratings can be explained by the individual difference variables we assessed (i.e., age, gender, general interest in magic tricks, and experience in performing the trick) by including these variable as additional fixed-effect predictors in the model. We also included a fixed-effect of trial number and its random slopes as an additional within-person predictor to explore the potential role of familiarization in epistemic emotions. Table 4 reports the results. Across epistemic emotions there is a consistent age effect, suggesting that older participants tended to have higher overall epistemic emotions, $(\beta \mathrm{s}=0.02, p \mathrm{~s}<.01)$. On the other hand, confidence was negatively associated with age $(\beta=-0.02, p<.01)$. There were no statistically significant gender differences $(-0.20 \leq \beta \mathrm{s} \leq 0.03, p \mathrm{~s}>.05)$. General interest in magic tricks is significantly and positively associated with epistemic emotions and confidence $(0.16 \leq \beta \mathrm{s} \leq$ $0.35, p \mathrm{~s}<.001)$. Experience with magic tricks has a strong positive association with confidence $(\beta=1.17, p<.001)$, and a weak positive relationship with interest $(\beta=0.38, p<.05)$. Finally, number of trials was negatively associated with epistemic emotions and confidence, indicating that there was a general declining trend for these ratings over trials $(-0.14 \leq$ $\beta \mathrm{s} \leq(-0.08, p \mathrm{~s}<.001)$.

To further examine the differentiation of these epistemic emotions, we also computed the correlations between surprise in response to the trick, interest in the trick, confidence in the solution, and curiosity in the solution at the within-person level. More specifically, we calculated within-person correlations for each participant (using video clips as the unit of analysis) and then computed the mean and SD of the correlations across participants (please see Table 5). Surprise in response to the trick, interest in the trick, and curiosity in the solution were highly correlated; however, there are also considerable individual differences (i.e., SD is relatively high), indicating that these three epistemic emotions are overlapping but distinct concepts, especially for particular individuals (Fayn et al. 2019). The distributions of the within-person correlations were all unimodal but the distribution was also substantially skewed given the limit of correlation coefficients $(-1 \leq$ $r \leq 1)$ and large individual differences. For completeness, we also computed a between-person correlation and have reported it in Appendix Table 8. As is typical with correlations of aggregated scores (Robinson, 1950), the between-person correlation between epistemic emotions is very high.

\section{Stimulus availability}

The final set of MagicCATs video clips is available upon request for research purpose. The request procedure is posted to Open Science Framework (https://osf.io/ad6uc/) along with the stimulus list (equivalent to Tables 6 and 7) and raw rating data.

Table 2 Variance components of the ratings

\begin{tabular}{llll}
\hline & Participant variance & Video clip variance & Participant x video variance \\
\hline Surprise in response to the trick & $37.9 \%$ & $7.4 \%$ & $54.7 \%$ \\
Interest in the trick & $37.3 \%$ & $7.2 \%$ & $55.5 \%$ \\
Confidence in the solution & $36.3 \%$ & $7.1 \%$ & $56.6 \%$ \\
Curiosity in the solution & $42.8 \%$ & $4.9 \%$ & $52.3 \%$ \\
\hline
\end{tabular}


Table 3 The variance components of each factor and their interactions

\begin{tabular}{ll}
\hline Participant & $34.6 \%$ \\
\hline Video & $6.2 \%$ \\
Emotion type & - \\
Participant x video & $39.0 \%$ \\
Video x emotion type & $0.2 \%$ \\
Participant x emotion type & $4.9 \%$ \\
Participant x video x emotion type & $15.0 \%$ \\
\hline
\end{tabular}

\section{Discussion}

The current article introduces 166 magic trick video clips (MagicCATs) as a novel stimulus set to induce epistemic emotions. MagicCATs include a variety of magic tricks with various lengths (8-155 s) and diverse materials (e.g., playing cards, coins, sponges etc.), making it easy for researchers to select and use the subset of stimuli best suited to their own research purposes. Furthermore, rating results showed sufficient within-person variance with moderate mean levels of epistemic emotions, meaning that these video clips are suitable to examine these emotions on a trial-by-trial basis. MagicCATs video clips are available for research purpose, and stimulus list and raw rating data are also available online (please go to https://osf.io/ad6uc/).

The mixed-effects modeling analysis indicated that there is substantial within-person variation of the ratings of epistemic emotions across different video clips. This is a useful property for an experimental stimulus set and these results demonstrated its capability to capture within-person variation of these emotions. However, the majority of this within-person variance came from participant $x$ video clip effects, meaning that there are substantial individual differences in which magic tricks were found surprising, curious, and interesting by participants (see Fastrich et al., 2017 for a similar finding with trivia questions). Therefore, when examining epistemic emotions with these stimuli it may be ideal to assess these epistemic emotions on a participant-by-participant basis. Of course, video variance was still present, and therefore, it is possible for future studies to rely on the aggregated ratings reported in the Appendix Table 7 to compare, for example, response between high vs. low curiosity magic video clips. However, the results should be interpreted with caution given the potential for large individual differences. It is worth noting that we also observed large participant variance that is comparable to the participant $\mathrm{x}$ video variance (Table 3). This variance may reflect general response bias but suggest possible individual differences in the overall tendency for participants to experience epistemic emotions.

One important research question for the future is to identify the source of these large individual differences. As the first step, we explored some basic demographic variables that we assessed in this experiment. First, older participants tended to have higher overall epistemic emotions. These findings are consistent with previous studies using trivia questions (Fastrich et al., 2017; McGillivray et al., 2015) but somewhat contradictory with a declining trend in curiosity-related personality traits in older age groups (Sakaki, Yagi, \& Murayama, 2018). On the other hand, confidence was negatively associated with age, which is also consistent with the previous study (Jay, 2016). Second, there were no statistically significant gender differences. Gygax et al. (2019) reported that males are more motivated to discover how tricks are done than females, which is inconsistent with our results for curiosity and confidence in solution. There are some methodological differences (e.g., the participants were asked to report the solution they had guessed in their study) and the future research would be necessary for clarity in what gender differences exists in which contexts. It is possible that other basic demographic variables such as culture can explain individual differences. Unfortunately, we only collected the data from US participants and could not analyze potential cultural differences. Because we provide all the experimental materials and programs online (code for the experiment is also available on request), we are hoping that those who are interested in the topic will conduct follow-up studies with different populations to examine the role of culture in the subjective experiences of epistemic emotions. Note that, using generalizability theory, our variance decomposition estimates (Table 2) allow researchers to determine the number of video clips to be used to reliably assess such individual differences (see Brennan, 2001 for formulas).

Table 4 Fixed effects (standard errors) predicting ratings of epistemic emotions in mixed-effects modeling

\begin{tabular}{lllll}
\hline & Surprise in response to the trick & Interest in the trick & Confidence in the solution & Curiosity in the solution \\
\hline Intercept & $3.29 * * *(0.36)$ & $3.35 * * *(0.33)$ & $4.17 * * *(0.37)$ & $3.02 * * *(0.38)$ \\
Trial number & $-0.08 * * *(0.02)$ & $-0.12 * * *(0.02)$ & $-0.11 * * *(0.02)$ & $-0.14 * * *(0.02)$ \\
Age & $0.02 * *(0.01)$ & $0.02 * *(0.01)$ & $-0.02 * *(0.01)$ & $0.02 * *(0.01)$ \\
Gender (male:0, female:1) & $0.03(0.16)$ & $-0.07(0.15)$ & $-0.20(0.17)$ & $-0.03(0.17)$ \\
General interest in magic & $0.26 * * *(0.04)$ & $0.31 * * *(0.04)$ & $0.16 * * *(0.04)$ & $0.35 * * *(0.04)$ \\
Experience in performing magic & $0.26(0.19)$ & $0.38 *(0.18)$ & $1.17 * * *(0.20)$ & $0.19(0.21)$ \\
\hline
\end{tabular}

$* p<.05, * * p<.01, * * * p<.001$ 
1: surprise in response to the trick

2: interest in the trick

$0.75(0.27,-2.43)$

$-0.45(0.36,1.16)$

$0.67(0.27,-1.99)$
$-0.38(0.36,1.11)$

$0.70(0.26,-2.00)$
$-0.42(0.39,1.09)$

Note: All correlations are statistically significant $(p \mathrm{~s}<.001)$. Numbers in parentheses represent SD and skewness across participants.

It is worth noting that the curiosity and interest ratings used in the current experiment may have slightly different meanings than those used in other studies on curiosity and interest. Specifically, curiosity ratings in the current experiment asked whether participants were curious about how the trick was done (i.e., curiosity in the solution), whereas interest ratings asked whether they were interested in the magic tricks themselves (i.e., interest in the trick). Curiosity in the solution focused on the subjective motivation to close the knowledge gap (Loewenstein, 1994), while interest in the trick focused more on the positive emotional feelings due to the apparent uncertainty and impossibility of the trick (Silvia, 2005). However, some other studies (e.g., Fastrich et al., 2017; McGillivray et al., 2015) operationalized the feeling of interest as the satisfying of curiosity (e.g., the positive feelings when seeing the answer of a trivia questions). Some other researchers, especially in the field of education, define interest more broadly in relation to learner's goals, values, and pre-existing knowledge (for a review, see Hidi \& Renninger, 2019). Our labeling of curiosity and interest are rather ad hoc: we simply used the terms in a way that participants can intuitively understand the focus of these feelings, i.e., curiosity in the solution vs. interest in the magic trick. In fact, we are hesitant to commit to the debate over the exact definitions of curiosity and interest (for details on our view, see Murayama, Fitzgibbon, \& Sakaki, 2019). However, researchers should bear in mind differences in the conceptualizations of curiosity and interest when interpreting the findings reported in the current article (see also Shin \& Kim, 2019).

Some additional points are worth discussing. First, our findings from the rating analysis may have a limitation in that we relied on a single-item measure to assess epistemic emotions, which are expected to be less reliable than multiple-item measures. However, we believe that simple subjective emotional feelings such as surprise can be assessed reliably and validly with a single-item measure (see also Diamantopoulos et al., 2012), and in fact most of the previous studies used a single-item measure to assess such epistemic emotions and found meaningful relations with other variables (e.g., Kang et al., 2009; Vogl et al., 2019). Even so, we need to wait for an empirical investigation to understand the extent of the problem when using single-item measures to examine epistemic emotions. Second, although we focused on the emotions of curiosity, interest, and surprise, other types of emotions may be experienced when people see magic tricks. For example, Leddington (2016) argued that the heart of the experience of magic is a conflict between "intellectual belief (the magic is impossible)" and "emotional belief (the magic is actually happening)." Further research would be required to investigate such emotions as well. Third, we observed that the number of trials was negatively associated with epistemic emotions and confidence, indicating that there was a general declining trend for these ratings over trials, perhaps reflecting a familiarization effect. Researchers who use MagicCATs should take care of this declining trend when they decide how many tricks they use in their studies. Fourth, the variance decomposition analysis and within-person correlation suggest that the three types of epistemic emotions we assessed are substantially overlapping even if they also exhibited some unique variances. The high inter-correlation between epistemic emotions is consistent with previous studies and not surprising given that these epistemic emotions are likely to be the causes or consequences of one another (e.g., Vogl et al., 2019, 2019). As all the ratings were assessed soon after each other, response bias might have played some role too (Podsakoff et al., 2003). However, these findings also suggest the importance of assessing and including these emotions together in an empirical study when researchers are interested in examining unique aspects of each specific type of epistemic emotions. Finally, although we did our best to control for various aspects of the video clips (e.g., background, expression of magicians, etc.), there are notable differences between the magic tricks. For example, running times vary widely between the video clips, and there are some video clips which have subtitles and/ or show a third person (e.g., a person to pick a card). These factors can be confounding in experimental work. However, these variations were necessary in order to ensure the generalizability of experimental findings from these stimuli. Researchers can easily control the differences between the videos by pre-screening the video clips according to the aims of studies. We are hoping to expand the collection further so that it is easier for researchers to select video clips that fit well with their research questions.

Author note We are grateful for the magicians (including Shota Irieda, Ohkubo Kohei and Alvaro Argente) for producing magic tricks for our 
research. We thank the members of Kyoto University Magician's Association for giving us some information of magic tricks. This research was supported by the Marie Curie Career Integration Grant (award Number CIG630680); JSPS KAKENHI (Grant Numbers 15H05401; 16H06406, 18H01102; 18K18696), F. J. McGuigan Early Career Investigator Prize from American Psychological Foundation; Jacobs
Foundation Research Fellowship, and the Leverhulme Trust (Grant Numbers RPG-2016-146 and RL-2016-030).

Open practice statement The data and materials for the experiment are available at https://osf.io/ad6uc/, and the experiment was not preregistered.

\section{Appendix}

Table 6 Detailed information about MagicCATs

\begin{tabular}{|c|c|c|c|c|c|c|c|}
\hline Magic ID & Name & Credit & $\begin{array}{l}\text { Phenomena } \\
\text { Category }\end{array}$ & Materials & Length & Subtitle & Brief description \\
\hline K1 & Deck vanish & Unknown & Disappearance & Cards & 0:00:18 & No & The deck vanishes into a black box \\
\hline K2 & $\begin{array}{l}\text { Color changing } \\
\text { book }\end{array}$ & Unknown & Color change & Book & 0:00:26 & No & $\begin{array}{l}\text { The sweets from a page in a } \\
\text { children's story book are poured } \\
\text { out onto the table from it }\end{array}$ \\
\hline K3 & $\begin{array}{l}\text { Ladybag magic } \\
\quad \text { (Paddle move) }\end{array}$ & Unknown & Color change & Knife & 0:00:25 & No & $\begin{array}{l}\text { A magician has a leaf on which two } \\
\text { ladybirds appear on either side } \\
\text { before magically disappearing }\end{array}$ \\
\hline K4 & Insta Cube & Craig Nichols & Other & Rubix Cube & 0:00:30 & No & $\begin{array}{l}\text { The magician magically solves the } \\
\text { Rubix Cube by spinning it in the } \\
\text { air }\end{array}$ \\
\hline K5 & $\begin{array}{l}\text { The Last Trick of } \\
\text { Dr. Daley_ver1 }\end{array}$ & Jacob Daley & Exchange & Cards & 0:00:35 & Yes & $\begin{array}{l}\text { Magician has four aces and places } \\
\text { the two red cards on the table but } \\
\text { when he reveals the cards, he is } \\
\text { actually holding the red cards and } \\
\text { the black cards are on the table }\end{array}$ \\
\hline K6 & Ace assembly & Alex Elmsley & Transportation & Cards & 0:00:41 & Yes & $\begin{array}{l}\text { An ace is placed onto the table and } \\
\text { three cards on top - all of which } \\
\text { turn out to be aces }\end{array}$ \\
\hline K7 & Card Warp & Roy Walton & Other & Cards & 0:00:33 & No & $\begin{array}{l}\text { Magician has a black and a red card. } \\
\text { He folds the red card in half and } \\
\text { then does the same with the black } \\
\text { card before slotting the black card } \\
\text { in between the folding of the red } \\
\text { one. He folds the cards back on } \\
\text { themselves and then pulls the } \\
\text { card in the middle out revealing } \\
\text { that the middle card is now the } \\
\text { red one. He folds them back once } \\
\text { again, revealing that it is in fact } \\
\text { the black card in the middle }\end{array}$ \\
\hline K8 & Card change & Unknown & Color change & Cards & 0:00:08 & No & Card changes with a small gesture \\
\hline K9 & Four aces location & Unknown & Assembly & Cards & 0:00:50 & No & $\begin{array}{l}\text { Magician deals four decks onto the } \\
\text { table each starting with an ace. It } \\
\text { turns out all the aces end up in } \\
\text { one pile and the others are made } \\
\text { up of the same cards }\end{array}$ \\
\hline K10 & linking pin & Dan Garrett & Penetration & Safety pin & $0: 00: 31$ & No & $\begin{array}{l}\text { Safety pins magically interlock } \\
\text { without breaking the seal }\end{array}$ \\
\hline K11 & Stargazer & Alan Wong & Change & Rubber band & $0: 00: 25$ & No & $\begin{array}{l}\text { Magician has two elastic bands. He } \\
\text { makes several star shapes using } \\
\text { them and then produces a star } \\
\text { shaped elastic band }\end{array}$ \\
\hline K12 & Card toon & Dan Harlan & Take one & Cards & $0: 00: 33$ & No & $\begin{array}{l}\text { Volunteer chooses } 7 \text { of hearts. The } \\
\text { magician then shows the } \\
\text { audience the flip book story on } \\
\text { the cards which shows that a fairy } \\
\text { also chooses the } 7 \text { of hearts }\end{array}$ \\
\hline K13 & & & Penetration & Rubber band & 0:00:19 & No & \\
\hline
\end{tabular}


Table 6 (continued)

Magic ID Name Credit \begin{tabular}{l}
$\begin{array}{l}\text { Phenomena } \\
\text { Category }\end{array} \quad$ Materials $\quad$ Length Subtitle Brief description \\
\hline
\end{tabular}

$\begin{array}{rr}\text { Crazy Man's } & \text { Michael } \\ \text { Handcuffs } & \text { Ammar }\end{array}$

K14

Quick as a wink Unknown

Take one

Cards

0:00:35 Yes

\begin{tabular}{|c|c|c|c|c|c|c|}
\hline K15_Long & Chicago Opener & $\begin{array}{l}\mathrm{Al} \text { Leech and } \\
\text { Frank } \\
\text { Everhart }\end{array}$ & $\begin{array}{l}\text { Take one/ color } \\
\text { change }\end{array}$ & Cards & 0:01:13 & Yes \\
\hline K15_Short & Chicago Opener & $\begin{array}{l}\text { Al Leech and } \\
\text { Frank } \\
\text { Everhart }\end{array}$ & $\begin{array}{l}\text { Take one/ color } \\
\text { change }\end{array}$ & Cards & 0:00:37 & No \\
\hline K16_Long & Ambitious Card & Gustav Alberti & Transportation & Cards & $0: 01: 12$ & Yes \\
\hline K16_Short & Ambitious Card & Gustav Alberti & Transportation & Cards & 0:00:31 & No \\
\hline K17 & Slop Shuffle & Sid Lorraine & Take one & Cards & 0:00:46 & No \\
\hline K18 & $3 \mathrm{D}$ advertising & Henry Evans & Materialization & Cards & 0:00:22 & No \\
\hline K19_Long & Chop Cup & Al Wheatley & Transportation & Cups and balls & 0:00:31 & No \\
\hline K19_Short & Chop Cup & Al Wheatley & Transportation & Cups and balls & $0: 00: 19$ & No \\
\hline K21_Long & Bizarre Twist ver1 & Paul Harris & Color change & Cards & $0: 00: 43$ & No \\
\hline K21 Short & Bizarre Twist ver1 & Paul Harris & Color change & Cards & $0: 00: 17$ & No \\
\hline K22_Long & Three-card Monte & Shoji Takahito & Exchange & Cards & $0: 00: 43$ & No \\
\hline
\end{tabular}

0:00:23 No

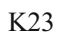

K24

K25

K27
Wonder Pen A

Tration

Bill switch

Spellbound

Rising card
Doug Edwards Penetration

Unknown

Dai Vernon

Unknown
Color change

Color change

Psychokinesis
Pen/ Bill

Bill

Coin

Cards
Magician has two elastic bands and tangles them up. They then become untwisted

Volunteer selects 2 of diamonds and places it back in the deck. Then he sandwiches the deck with a Joker on each end. Then he throws the card from one hand to the other and sandwiched between the two Jokers is the volunteer's selected card

Volunteer selects a card and put it back to a deck then this card becomes a colored card

Volunteer selects a card and put it back to a deck then this card becomes a colored card

Volunteer selects and signs a card. Magician put it inside the deck and the signed card appeared on the top repeatedly

Volunteer selects and signs a card. Magician put it inside the deck and the signed card appeared on the top repeatedly

Volunteer selects a card and the magician shuffled a deck. This card is the only one that has the opposite side

Pack of cards comes out of a piece of paper

balls in a cup warps and turns into a toy rabbit

balls in a cup warps and turns into a toy rabbit

A card flips with a shorthand gesture

A card flips with a shorthand gesture

Volunteer is shown three cards; one red and two black cards. The magician places the cards face down on to the table in the same order that he presented the cards to the volunteer. The magician then asks the volunteer to point to the red card but when the magician turns the card over it is in fact a black card

Volunteer is shown three cards; one red and two black cards. The magician places the cards face down on to the table in the same order that he presented the cards to the volunteer. The magician then asks the volunteer to point to the red card but when the magician turns the card over it is in fact a black card

Magician puts a hole through the money bill but then reveals that the hole disappears

$£ 10$ note is transformed into a $£ 20$

Coin is changed back and forth from silver to copper 
Table 6 (continued)

Magic ID Name Credit \begin{tabular}{l}
$\begin{array}{l}\text { Phenomena } \\
\text { Category }\end{array} \quad$ Materials $\quad$ Length Subtitle Brief description \\
\hline
\end{tabular}

Volunteer is asked to choose a card from the deck. They choose a card and then place it back into the middle of the deck. The magician then shuffles the card and waves his hand over the deck as the chosen cards rises from the pack

\begin{tabular}{|c|c|c|c|c|c|}
\hline $\mathrm{K} 28$ & $\begin{array}{l}\text { Bottle from paper } \\
\text { bag }\end{array}$ & Unknown & Appearance & Bottle & 0:00:13 \\
\hline K29 & Bottle production 1 & Unknown & Appearance & Bottle & 0:00:15 \\
\hline K30 & Bottle production 2 & Unknown & Appearance & Bottle & 0:00:13 \\
\hline K31 & HANASAKI-crystal & $\begin{array}{l}\text { Sugawara } \\
\text { Shigeru }\end{array}$ & Appearance & Flower & $0: 00: 12$ \\
\hline K32 & Billiard Ball 1 & Unknown & Appearance & Billiard Ball & 0:00:11 \\
\hline K33 & Billiard Ball 2 & Unknown & Color change & Billiard Ball & 0:00:11 \\
\hline K34 & Rope through body & Unknown & Penetration & Rope & 0:00:11 \\
\hline K35_Long & $\begin{array}{l}\text { Professor's } \\
\text { nightmare }\end{array}$ & $\begin{array}{c}\text { Bob Carver } \\
\text { and Hen } \\
\text { Fetsch }\end{array}$ & Other & Rope & 0:00:27 \\
\hline K35_Short & $\begin{array}{l}\text { Professor's } \\
\text { nightmare }\end{array}$ & $\begin{array}{c}\text { Bob Carver } \\
\text { and Hen } \\
\text { Fetsch }\end{array}$ & Other & Rope & 0:00:13 \\
\hline S1 & Play it straight & John Bannon & Take one & Cards & 0:00:52 \\
\hline S2 & Quick Coincidence & Unknown & Take one & Cards & $0: 00: 32$ \\
\hline S3_Long & Bizarre Twist_ver2 & Paul Harris & Color change & Cards & $0: 00: 38$ \\
\hline S3_Short & Bizarre Twist_ver2 & Paul Harris & Color change & Cards & 0:00:20 \\
\hline S4 & $\begin{array}{l}\text { Torn \& Restored } \\
\text { Transpo }\end{array}$ & $\begin{array}{l}\text { David } \\
\quad \text { Williamson }\end{array}$ & $\begin{array}{l}\text { Restoration/Take } \\
\text { one }\end{array}$ & Cards & 0:00:46 \\
\hline
\end{tabular}

Magician produces a water bottle from a paper bag

Magician produces a water bottle from a silk

Magician produces a water bottle from his jacket

Magician produces a flower from a glass box

Magician produces a red ball from his hand

Magician turns a red ball into a white one using hand gestures. Then he turns it back into the red one

Magician ties rope around neck but manages to untie it

Magician has three ropes of various different lengths and manages to make them all the same size

Magician has three ropes of various different lengths and manages to make them all the same size

Magician shuffles card, revealing one suit is facing upwards throughout the deck and is in order

Volunteer selects four cards, all of which turn out to be the aces

Card flips or changes to another color with a quick gesture

Card flips or changes to another color with a quick gesture

Magician shows the audience a card which he then rips up. Then he shows the audience another card, but this time waves the card over the ripped up one, revealing that the two cards have swapped places

S5

S6
Drible force

1 to 4

Four cards change

Princess card trick
Unknown

Unknown

Unknown

Henry Hardin
Mind reading

Appearance

Change

Mind reading
Cards

Cards

Cards

Cards
0:00:22 No

0:00:21 No

0:00:13 Yes

0:00:34 Yes
The magician verbally points to the card that was seen by volunteer

Volunteer selects one card which then magically turns into four - all of which are the same e.g., all Queens

Four different cards change to four kings

Six cards are placed on the table and the audience is asked to remember one of the cards. The magician then removes all of the cards from the table, laying one of the cards to the side but face down. He then places the cards back down on the table again revealing that the audience 
Table 6 (continued)

Magic ID Name Credit $\begin{aligned} & \text { Phenomena } \\ & \text { Category }\end{aligned} \quad$ Materials $\quad$ Length Subtitle Brief description

Blanc Deck
Ultra Visual
Nightshades
Cigarette through
the coin

Moving a hole
Unknown

Mark Allen and Paul Harris

Unknown

L. Vosburgh Lyons

Coins across

Powder sugar to block sugar

Ring through the glass

Gipsy thread

Multum in parvo

Bazar de Magia Other

Unknown

Dan Hauss

flow
Giant Appearing Straw

Spoon bending

Bill in lemon

Thunderbird

Handkerchief in

Bread

Rope act

Water Vanish

Dresscode

sticky situation

Chinese Stick

Wari-vanish
Unknown

Unknown

Emil Jarrow and Doc

Eason

Lee Asher

Unknown

Unknown

Unknown

Andy Leviss

Change

Restoration

Unknown

Other

Takahito Shoji Disappearance

Appearance

Transportation

\section{Cards}

Bill

Cigarette/ Coin

Cards

Cards

Coin

Sugar

Ring/ Grass

Thread

Milk/ Grass

Appearance

Other

Appearance

Straw

Spoon

Bill/Lemon

Cards

0:00:16 Yes

Handkerchief/Bread 0:00:52 No

Rope

0:00:24 No

Water

0:00:31 No

\section{T-shirts}

Chewing gum

Sticks member's chosen card is no longer in the deck

Magician turns a deck of cards into a blank deck

Magician draws glasses onto Queen on $£ 10$ note and then makes the glasses move

Magician pushes a cigarette through a coin and then reveals that there is no hole

A hole is hole-punched into the corner of a card. The magician then moves the hole to a different corner and then reveals that it's actually a black spot on the card

Magician has a coin in each of his hands. They both end up in one hand

Magician turns powdered sugar into a block of sugar

Magician places ring on the stem of a glass without breaking it

Magician cuts piece of string in several places and then magically puts it back together whole.

Magician pours milk from a small glass into a bigger one but still manages to fill the bigger glass full of milk. He continues this process with bigger glasses each time and still manages to fill the bigger glasses.

Magician pulls out 3 boxes with flowers in from a paper bag

Magician asks volunteer to hold hand over a water bottle. When turned upside down the water does not pour out until the magician gestures

Two magicians pull out giant straw from a brown paper bag

Magician bends a spoon using fingers

Magician asks volunteer to sign piece of paper which then magically appears inside a lemon

Cards magical appear in magicians' hand

Handkerchief appears from bread

Magician cuts rope with fingers and then mends the broken rope

Magician pours water into cup from bottle and then pours the water into another cup but when he tips it upside down, no water spills out

Magician changes t-shirts very quickly when he turns around

Magician transforms a chewed piece of gum back into its packaging

Magician pulls strings through a stick which makes the other string in the other stick move 
Table 6 (continued)

\begin{tabular}{|c|c|c|c|c|c|c|c|}
\hline Magic ID & Name & Credit & $\begin{array}{l}\text { Phenomena } \\
\text { Category }\end{array}$ & Materials & Length & Subtitle & Brief description \\
\hline & & & & & & & $\begin{array}{l}\text { Magician places a pair of chopsticks } \\
\text { into envelope and proceeds to } \\
\text { crush the envelope and its } \\
\text { contents into a paper ball }\end{array}$ \\
\hline S32 & Self-Tying Shoelace & Jay Noblezada & Other & Shoes & 0:00:14 & No & $\begin{array}{l}\text { Magician ties his shoelace without } \\
\text { using his hands }\end{array}$ \\
\hline S33_Long & Swallowing balloon & Steve Bedwell & Other & Balloon & 0:00:52 & No & $\begin{array}{l}\text { Magician eats a long balloon while it } \\
\text { is full of air }\end{array}$ \\
\hline S33_Short & Swallowing balloon & Steve Bedwell & Other & Balloon & 0:00:45 & No & $\begin{array}{l}\text { Magician eats a long balloon while it } \\
\text { is full of air }\end{array}$ \\
\hline H1 & Reduction & $\begin{array}{l}\text { Nicholas } \\
\text { Lawrence }\end{array}$ & Disappearance & Cards & 0:00:12 & No & A deck of cards reduced to 10 \\
\hline $\mathrm{H} 2$ & The brade & $\begin{array}{l}\text { Katsuya } \\
\quad \text { Masuda }\end{array}$ & Restoration & Cutter knife/Bill & 0:00:46 & No & $\begin{array}{l}\text { Magician folds a } £ 10 \text { note in a piece } \\
\text { of paper and cuts through them } \\
\text { with a knife. He reveals that the } \\
£ 10 \text { is still intact afterwards }\end{array}$ \\
\hline H3 & Coin assembly & Unknown & Assembly & Coins/ Cards & 0:00:24 & No & $\begin{array}{l}\text { Magician hides four coins under } \\
\text { four cards and reveals that the } \\
\text { coins swap places under the cards } \\
\text { in several different ways }\end{array}$ \\
\hline H4_Long & $\begin{array}{l}\text { Coin assembly \& } \\
\text { Reverse }\end{array}$ & Unknown & Assembly & Coin/Cards & 0:00:57 & No & $\begin{array}{l}\text { Magician has four coins and two } \\
\text { cards. He places the coins in each } \\
\text { corner of the table and places two } \\
\text { cards on top of the two top coins. } \\
\text { He picks up one of the two } \\
\text { remaining coins and makes it } \\
\text { disappear from his hand and then } \\
\text { reveals it is now underneath one } \\
\text { of the cards with the other coin }\end{array}$ \\
\hline H4_Short & $\begin{array}{l}\text { Coin assembly \& } \\
\text { Reverse }\end{array}$ & Unknown & Assembly & Coin/Cards & 0:00:21 & No & $\begin{array}{l}\text { Magician has four coins and two } \\
\text { cards. He places the coins in each } \\
\text { corner of the table and places two } \\
\text { cards on top of the two top coins. } \\
\text { He picks up one of the two } \\
\text { remaining coins and makes it } \\
\text { disappear from his hand and then } \\
\text { reveals it is now underneath one } \\
\text { of the cards with the other coin }\end{array}$ \\
\hline H5 & The ten count & Unknown & Transportation & Sponge & 0:00:12 & No & $\begin{array}{l}\text { Two sponge balls each behind one } \\
\text { hand end up in one hand }\end{array}$ \\
\hline H6 & Ball to Cube sponge & Unknown & Change & Sponge & 0:00:15 & No & Two sponge balls turn into a cube \\
\hline H7 & Salt and Silver & $\begin{array}{r}\text { Giovanni } \\
\text { Livera }\end{array}$ & Transportation & Coin & 0:00:33 & No & $\begin{array}{l}\text { Coin appears everywhere around the } \\
\text { salt case }\end{array}$ \\
\hline H8 & Capture & Luke Dancy & Other & Coin/ Smartphone & 0:00:40 & No & $\begin{array}{l}\text { Magician puts coin into phone and } \\
\text { then the coin comes out of the } \\
\text { phone and into the volunteers' } \\
\text { hand }\end{array}$ \\
\hline H9 & Touch & Hanson Chien & Transportation & Rubber band & 0:00:18 & No & $\begin{array}{l}\text { The magician has an elastic band on } \\
\text { his hand which then magically } \\
\text { ends up on the volunteers' hand }\end{array}$ \\
\hline H10 & God hand & Lubor Fiedler & Restoration & Cards & 0:00:20 & No & $\begin{array}{l}\text { Card that's split into four pieces is } \\
\text { magically put back together }\end{array}$ \\
\hline H11 & V-Rank Card & $\begin{array}{l}\text { Katsuya } \\
\text { Masuda }\end{array}$ & Other & Cards & $0: 00: 25$ & Yes & $\begin{array}{l}\text { Magician shows a card with a red } \\
\text { back and a blank back. Then he } \\
\text { changes the blank back into the } \\
\text { red back and vice versa }\end{array}$ \\
\hline H12 & $\begin{array}{l}\text { One hand color } \\
\text { change }\end{array}$ & Shin Lim & Color Change & Cards & 0:00:08 & No & $\begin{array}{l}\text { The magician waves his hand over } \\
\text { the card placed on the table which } \\
\text { changes to a different card }\end{array}$ \\
\hline H13 & Frozen & Adam Grace & Other & Coin & 0:01:09 & No & $\begin{array}{l}\text { Magician takes a coin from } \\
\text { volunteer and freezes it in a paper } \\
\text { napkin }\end{array}$ \\
\hline H14 & Insane & Andy Newman & Prediction & Cards & 0:01:11 & No & $\begin{array}{l}\text { Magician has the King of hearts as a } \\
\text { prediction and asks the volunteer }\end{array}$ \\
\hline
\end{tabular}


Table 6 (continued)

Magic ID Name Credit $\begin{aligned} & \text { Phenomena } \\ & \text { Category }\end{aligned} \quad$ Materials Length Subtitle Brief description

H15

H16

H18

$\mathrm{H} 22$

$\mathrm{H} 24$

H 25

H26

H28

H29

H31

H32

H33

H34

H35

H36

H37

H38

H39

$\mathrm{H} 40$
Unbalance

Healed and sealed

Guillotine

Fish appearance

Sponge appearance

Tani Hideki

Sponge routine

Unknown

John Kennedy

Mind reading

Cards

0:01:01 No

Other

Appearance

Appearance

Transportation

Sponge
Creis Co. 1td

Self-folding bill

$\mathrm{X}$ change

Tagged

UFO card

Cardcase color change

4 by 4

Big bang

Tanging

Envy-lope

iVanish

Indecent

Macro psychic

Finger drop

revolution

Floating cigarette

Passin' Thru

Levitator
Cards

Bill

Henry Evans Mind reading

Stefan Schutzer Psychokinesis

Julio Montoro Materialization

Cards/Coin

Cards/ Necklace

Richard

Sanders

Unknown

Shin Lim

Shin Lim

Color change

Krisjian Pipho Psychokinesis

Unknown

Disappearance

Brandon David Disappearance and Chris

Turchi

Ben Seidman

Wayne

Houchin

Creis Co. ltd Psychokinesis PROMA Web Other

Shop

Steve Fearson

Floating

Kevin Parker

Penetration

Floating

Coin/ Bottle
0:01:26 No

$0: 00: 13$ No

0:00:59 No

0:00:39 No

0:00:08 No

0:00:15 No

0:00:20 No

0:00:16 No

0:00:22 No

0:00:42 No

0:00:25 No

0:00:28 Yes 0:00:28 Yes

0:00:24 No

0:00:31 No

0:00:14 Yes
0:00:36 No

to shuffle the deck. He then asks her to deal cards and stop when she likes. The card she stopped is the King of hearts

Magician is able to balance a toothpick on a deck of cards but the volunteer cannot

Magician pours coke into glass from an empty can

The magician uses a guillotine to slice breadsticks, then asks the volunteer to put her finger in. He slices the breadstick but not her finger

The magician unfolds a $£ 10$ note and drops a fish into a glass of water

Magician places ball of paper in participants hand and sets it alight, revealing a red sponge ball

Magician places on ball in the volunteer's hand and one in his own hand but reveals that both end up in the volunteer's hand

Volunteers each remember one specific card from the deck shown to them by the Magician. The magician then reads (out loud) the names of the cards that the volunteers remembered

This one is labelled as take 1

A $£ 10$ note folds itself into half

Volunteer signs card and magician then draws a coin on the back. The picture of the coin then turns into a real-life coin

Volunteer selects a card which then sticks to the magician's necklace at the end

Card flies around magician in a circle

Card case changes color

four red cards change into four blue ones

Magician breaks light bulb in a bag

Magician makes a cigarette disappear and then reappear

Volunteer signs a card which the magician then ends up pulling out of an envelope

Magician places coin into eye and then pulls it out of the other one

Volunteer signs card which the magician ends up pulling out of a Ziploc bag

Screw and bolt unscrew itself

Magician unscrews his finger and then shakes it back into place

A cigarette floats around the magician

Magician puts coin into a glass bottle without it breaking 
Table 6 (continued)

\begin{tabular}{|c|c|c|c|c|c|c|c|}
\hline Magic ID & Name & Credit & $\begin{array}{l}\text { Phenomena } \\
\text { Category }\end{array}$ & Materials & Length & Subtitle & Brief description \\
\hline & & $\begin{array}{l}\text { Andrew } \\
\text { Mayne }\end{array}$ & & & & & $\begin{array}{l}\text { Magician levitates from on top of a } \\
\text { box to the ground }\end{array}$ \\
\hline H41 & Sandwich Vanish & Shin Lim & Disappearance & Cards & 0:00:16 & No & $\begin{array}{l}\text { Card on the table is magically } \\
\text { changed into a different card with } \\
\text { a quick gesture }\end{array}$ \\
\hline Trick1 & $\begin{array}{l}\text { How to cheat at } \\
\text { poker }\end{array}$ & Alvaro Argente & Color change & Cards & $0: 00: 30$ & No & $\begin{array}{l}\text { The magician shuffles the cards and } \\
\text { turns four random cards into } 4 \\
\text { kings }\end{array}$ \\
\hline Trick2 & $\begin{array}{l}\text { Finding aces with } \\
\text { mistake }\end{array}$ & Alvaro Argente & Assembly & Cards & $0: 00: 53$ & No & $\begin{array}{l}\text { The magician shuffles the cards and } \\
\text { finds the four aces in the pack }\end{array}$ \\
\hline Trick3 & Triumph & Dai Vernon & Take one & Cards & 0:00:50 & Yes & $\begin{array}{l}\text { A card trick where some of the cards } \\
\text { end up face down and the other } \\
\text { half face up and the chosen card is } \\
\text { found in the middle }\end{array}$ \\
\hline Trick4 & Pressure & Daniel Garcia & Penetration & $\begin{array}{l}\text { Balloon/ Smart } \\
\text { phone }\end{array}$ & 0:00:42 & No & $\begin{array}{l}\text { The magician puts a mobile phone } \\
\text { inside a balloon with a simple } \\
\text { gesture of his hands }\end{array}$ \\
\hline Trick5 & Smoke in the veins & Alan Rorrison & Other & Smoke & $0: 00: 25$ & No & $\begin{array}{l}\text { The magician draws a dot on the } \\
\text { palm of his hand and then uses a } \\
\text { lighter to make a gesture under } \\
\text { his hand. The smoke then travels } \\
\text { up his arm and out through his } \\
\text { mouth }\end{array}$ \\
\hline Trick6_Short & Chop cup & Don Alan & Transportation & Cup and ball & $0: 00: 27$ & No & $\begin{array}{l}\text { The classic cup and ball routine } \\
\text { using only } 1 \text { cup and an egg }\end{array}$ \\
\hline Trick6_Long & Chop cup & Don Alan & Transportation & Cup and ball & 0:01:04 & No & $\begin{array}{l}\text { The classic cup and ball routine } \\
\text { using only } 1 \text { cup and an egg }\end{array}$ \\
\hline Trick7_Short & $\begin{array}{l}\text { Multiplying sponge } \\
\text { balls }\end{array}$ & Lybarger & Transportation & Sponge & 0:00:20 & No & $\begin{array}{l}\text { The magician gets the volunteer to } \\
\text { hold a foam ball which then } \\
\text { doubles in to two. He repeats the } \\
\text { trick and they then turn into three }\end{array}$ \\
\hline Trick7_Long & $\begin{array}{l}\text { Multiplying sponge } \\
\text { balls }\end{array}$ & Lybarger & Transportation & Sponge & $0: 00: 34$ & No & $\begin{array}{l}\text { The magician gets the volunteer to } \\
\text { hold a foam ball which then } \\
\text { doubles in to two. He repeats the } \\
\text { trick and they then turn into three. }\end{array}$ \\
\hline Trick8_Short & Icebreaker & Alvaro Argente & Take one & Cards & 0:00:39 & Yes & $\begin{array}{l}\text { The volunteer chooses a card and } \\
\text { places it into the deck. The } \\
\text { magician then shuffles the card, } \\
\text { revealing to the camera that the } \\
\text { selected card is not on the top nor } \\
\text { the bottom. Then with a gesture } \\
\text { of his hand, he transforms the top } \\
\text { card into the selected card. }\end{array}$ \\
\hline Trick8_Long & Icebreaker & Alvaro Argente & Take one & Cards & $0: 00: 56$ & Yes & $\begin{array}{l}\text { The volunteer chooses a card and } \\
\text { places it into the deck. The } \\
\text { magician then shuffles the card, } \\
\text { revealing to the camera that the } \\
\text { selected card is not on the top nor } \\
\text { the bottom. Then with a gesture } \\
\text { of his hand, he transforms the top } \\
\text { card into the selected card. }\end{array}$ \\
\hline Trick9 & $\begin{array}{l}\text { The Last Trick of } \\
\text { Dr. Daley }\end{array}$ & Jacob Daley & Exchange & Cards & $0: 00: 26$ & No & $\begin{array}{l}\text { The magician places two red cards } \\
\text { down and then reveals that they } \\
\text { are actually two black cards }\end{array}$ \\
\hline Trick10 & Aces color change & $\begin{array}{l}\text { Edward Marlo } \\
\text { and Alvaro } \\
\text { Argente }\end{array}$ & Color change & Cards & 0:00:52 & No & $\begin{array}{l}\text { The magician has four aces with red } \\
\text { backs. He then turns the back } \\
\text { color to blue. Eventually he } \\
\text { reveals that all of the aces have a } \\
\text { different color back }\end{array}$ \\
\hline Trick11 & Poker face & W. Ciuro & Take one & Cards & 0:01:18 & No & $\begin{array}{l}\text { The volunteer selects a card and } \\
\text { places it back into the deck. The } \\
\text { magician shuffles the cards and } \\
\text { then places four cards on the } \\
\text { table. One of the cards is the }\end{array}$ \\
\hline
\end{tabular}


Table 6 (continued)

\begin{tabular}{llll}
\hline Magic ID Name Credit & $\begin{array}{l}\text { Phenomena } \\
\text { Category }\end{array}$ & Materials & Length Subtitle Brief description
\end{tabular}

\begin{tabular}{|c|c|c|c|c|c|c|c|}
\hline & & & & & & & $\begin{array}{l}\text { selected card. The magician then } \\
\text { places a further } 4 \text { cards on the } \\
\text { table and reveals that the } 4 \text { th card } \\
\text { is actually the selected card. Then } \\
\text { he reveals that the other cards are } \\
\text { not the selected card }\end{array}$ \\
\hline Trick12_Short & Sandwich effect & Harry Lorayne & Transportation & Cards & $0: 00: 34$ & No & $\begin{array}{l}\text { The magician reveals that the } \\
\text { selected card is sandwiched } \\
\text { between two cards }\end{array}$ \\
\hline Trick12_Long & Sandwich effect & Harry Lorayne & Transportation & Cards & 0:01:46 & No & $\begin{array}{l}\text { The magician reveals that the } \\
\text { selected card is sandwiched } \\
\text { between two cards }\end{array}$ \\
\hline Trick13 & Inside a box & Dani Daortiz & Take one & Cards & $0: 00: 44$ & No & $\begin{array}{l}\text { The volunteer examines an empty } \\
\text { card box and then chooses a card } \\
\text { from the magicians' deck. With a } \\
\text { gesture, the magician reveals that } \\
\text { the card was in the box }\end{array}$ \\
\hline Trick14_Short & Rub-a-dub Vanish & Paul Stadleman & Take one & Cards & $0: 00: 37$ & No & $\begin{array}{l}\text { The volunteer chooses a card and } \\
\text { places it back into the deck. With } \\
\text { a gesture, the magician reveals } \\
\text { the selected card }\end{array}$ \\
\hline Trick14_Long & Rub-a-dub Vanish & Paul Stadleman & $\begin{array}{l}\text { Take } \\
\text { one/Disappear- } \\
\text { ance }\end{array}$ & Cards & 0:00:47 & No & $\begin{array}{l}\text { The volunteer chooses a card and } \\
\text { places it back into the deck. With } \\
\text { a gesture, the magician reveals } \\
\text { the selected card. The magician } \\
\text { then makes the selected card } \\
\text { disappear }\end{array}$ \\
\hline Trick15 & Invisible deck & Jor Berg & Prediction & Cards & $0: 00: 37$ & No & $\begin{array}{l}\text { Card a volunteer picked up. In } \\
\text { another deck, the card appeared } \\
\text { face down while the other cards } \\
\text { are face up }\end{array}$ \\
\hline Trick16_Short & Signed Transpo & Alvaro Argente & Take one & Cards & 0:00:59 & No & $\begin{array}{l}\text { Four cards (two red and two black) } \\
\text { are placed on top of the table. A } \\
\text { participant signs a card and places } \\
\text { it back into the pile. Then with a } \\
\text { gesture, the magician flicks the } \\
\text { signed card into the four cards on } \\
\text { the table }\end{array}$ \\
\hline Trick16_Long & Signed Transpo & Alvaro Argente & Take one & Cards & 0:01:42 & No & $\begin{array}{l}\text { Four cards (two red and two black) } \\
\text { are placed on top of the table. A } \\
\text { participant signs a card and places } \\
\text { it back into the pile. Then with a } \\
\text { gesture, the magician flicks the } \\
\text { signed card into the four cards on } \\
\text { the table. The magician then loses } \\
\text { the car and finds it again in his } \\
\text { pocket }\end{array}$ \\
\hline Trick17 & MST & $\begin{array}{l}\text { Mathew } \\
\text { Dowden }\end{array}$ & Other & Cards & 0:01:55 & No & $\begin{array}{l}\text { Volunteer signs the front of one card } \\
\text { and the back of another. The } \\
\text { magician transfers the signatures } \\
\text { onto the front and back of one } \\
\text { card }\end{array}$ \\
\hline Trick18_Long & Ambitious card & Gustav Alberti & Transportation & Cards & 0:01:22 & No & $\begin{array}{l}\text { The magician signs a card and } \\
\text { returns it to the middle of the } \\
\text { deck. He clicks his fingers and } \\
\text { reveals the card is now on top. } \\
\text { Then he bends the card and places } \\
\text { it back into the middle. After a } \\
\text { gesture, the card ends up on top } \\
\text { again }\end{array}$ \\
\hline Trick18_Short & Ambitious card & Gustav Alberti & Transportation & Cards & 0:00:31 & Yes & $\begin{array}{l}\text { The magician signs a card and } \\
\text { returns it to the middle of the } \\
\text { deck. He clicks his fingers and } \\
\text { reveals the card is now on top. }\end{array}$ \\
\hline
\end{tabular}


Table 6 (continued)

\begin{tabular}{|c|c|c|c|c|c|}
\hline Magic ID & Name & Credit & $\begin{array}{l}\text { Phenomena } \\
\text { Category }\end{array}$ & Materials & Length \\
\hline Trick19 & Card in the mouth & Unknown & Transportation & Cards & 0:01:03 \\
\hline Trick20_Short & Nut and rope & $\begin{array}{r}\text { Giovanni } \\
\text { Livera }\end{array}$ & Penetration & Nut/ Rope & $0: 00: 36$ \\
\hline Trick20_Long & Nut and rope & $\begin{array}{r}\text { Giovanni } \\
\text { Livera }\end{array}$ & Penetration & Nut/ Rope & $0: 01: 17$ \\
\hline Trick21 & Magic ring & Wayne Dobson & Penetration & Ring/Key & 0:01:09 \\
\hline Trick22_Long & Cups\&Balls & David Forrest & Penetration & Cups and balls & 0:01:06 \\
\hline
\end{tabular}

Trick22_Short

Cups\&Balls

David Forrest

Penetration

Cups and balls

0:00:33 Yes

Trick23_Short

Ace to King

Pepe Carroll

and Alvaro

Argente

Trick23_Long

Ace to King
Pepe Carroll
and Alvaro

Argente

Trick24

Cut by the card

Trick25

Do as I do

Copy cat

Bell on a card

Chinese linking rings

Trick29
Trick26

Trick27

Trick28

$$
\text { Scotch and Soda }
$$

Unknown Take one

Vicente Canuto Take one

Unknown

Take one

Alvaro Argente Transportation

Unknown

Penetration

Transportation/

Richard
Himber

Disappearance
Cards

Cards

Cards

Cards

Rings

Coins
Then he bends the card and places it back into the middle. After a gesture, the card ends up on top again

The volunteers selected card appears in the magician's mouth

The magician shows a metal nut and rope. It doesn't matter how many times he secures the nut with the rope, it always scape

The magician shows a metal nut and rope. It doesn't matter how many times he secures the nut with the rope, it always scape

The magician links the volunteers ring onto a key and then unlinks it

Three shot glasses are placed on the table and small pieces of paper scrunched into balls are put on top. The magician then shuffles the shot glasses around revealing the fire paper underneath has multiplied. Eventually he reveals a red ball underneath one of the shot glasses

Three shot glasses are placed on the table and small pieces of paper scrunched into balls are put on top. The magician then shuffles the shot glasses around revealing the fire paper underneath has multiplied. Eventually he reveals a red ball underneath one of the shot glasses

Four aces and two jacks are removed from the deck. One ace is placed on the table and the magician then finds the next cards and places them in order starting from the ace

Four aces and two jacks are removed from the deck. One ace is placed on the table and the magician then finds the next cards and places them in order starting from the ace

Find a card that the volunteer picked up

The magician gets the volunteer to copy his card shuffling and cutting. The volunteer ends up finding their card in the opposite deck

The magician searches spectator's card by cutting deck

The volunteers selected card appears under the bell

Magician links and unlinks several silver rings

The magician shows a silver and a copper coin. Every time he puts a coin in his pocket, the coin appears again in his hand. In the 
Table 6 (continued)

\begin{tabular}{llll}
\hline Magic ID Name Credit & $\begin{array}{l}\text { Phenomena } \\
\text { Category }\end{array}$ & Materials & Length Subtitle Brief description
\end{tabular}

Trick30

Mental Bend

Unknown

Bending

Trick31

Coin detection

Unknown

Take one

Trick32_Long

One coin routine

David Roth

Transportation

Trick32_Short

One coin routine

David Roth

Transportation

Pixel:

Omni deck

Paul Harris

Change

Trick35

Trick36_Long

Trick36 Short

Trick37

Trick38

Trick39

Trick40

Trick41
Four Kings

Three card monte

Unknown

Eddie Fetcher and Joshua

Jay

Four Kings

Impossible escape

bands

Classic

Disappearance

Milbourne

Disappearance/

Handkerchief

0:00:32 No

Mathieu Bich and Jon

Armstrong

Roy Kueppers

Coin bite

Silk Transformation Russ Walsh
Change
Cards/ Tiny plunger $\quad$ 0:00:51 No
Christopher Appearance
Coin

0:00:56 No

Cards/ Coin

0:00:38 No

Coin

0:00:42 No

Cards

0:00:55 No

end, all the coins disappear from his hand

The magician asks the audience for a coin. They signed it to be sure that is in fact their coin. Then the coins magically bend inside the closed fist of the audience

A card is selected and lost in the deck. Then, the magician shows a coin and makes it disappear.

When the cards are spread on the table, the coin can be seen in the middle of the extension... marking where the selected card is

The magician makes a silver coin disappear and reappear several times

The magician makes a silver coin disappear and reappear several times

A card is selected and lost in the deck. Then, the magician found a selected card using rubber band

Volunteer chooses and signs a card. The magician then places the deck in the volunteer's hand and finds the missing card. When the volunteer reveals the deck, it is in fact a clear block in the shape of a deck of cards

The volunteer has to track a card and the magician keeps swapping it to the middle

Two kings change into two jokers. Then, the magician finds four kings in the deck and finally he reveals that the color of the deck is different

Two kings change into two jokers An elastic band visually travels from finger to finger, then it travels again even when the fingers are secured with another elastic band

The magician closes his left fit around a silk, and makes it disappear. Then, he makes it appear from his right fist

The magician uses small plunger to pick out the card

The magician borrows a coin and visually "bites" a piece of it. Then, in a gesture, the coin is restored

The magician shows a silk, and in a gesture, turns it into a metal cane 


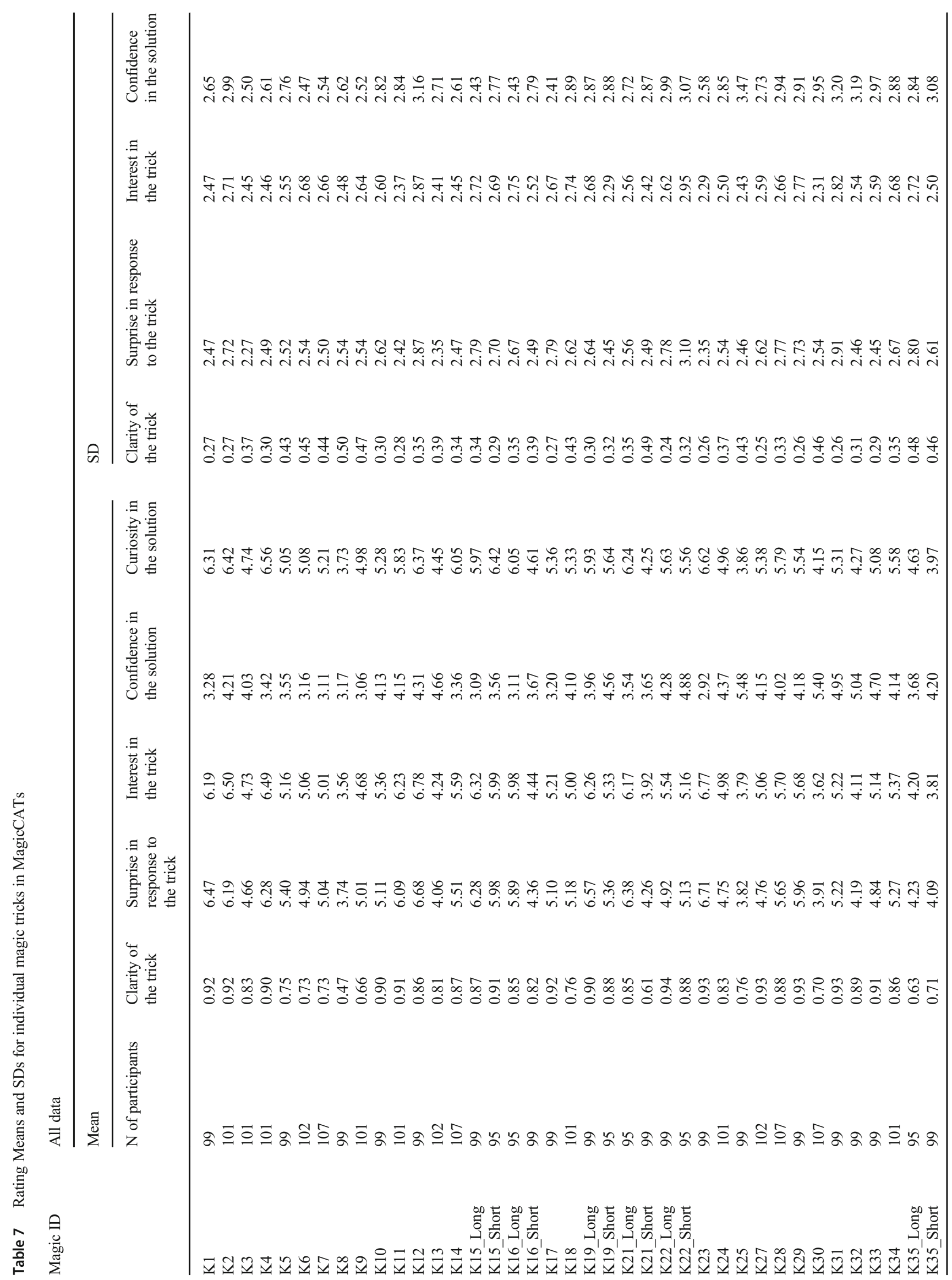




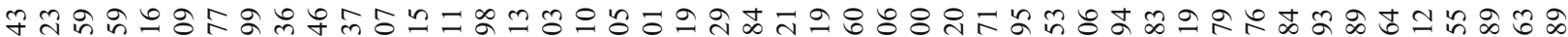

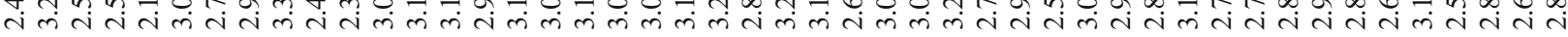

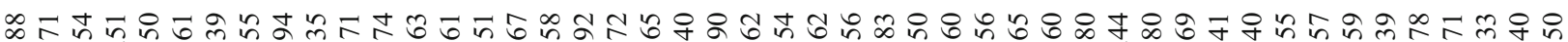

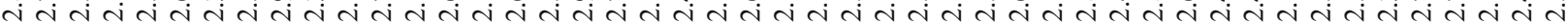

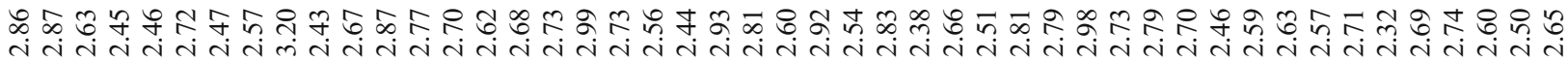

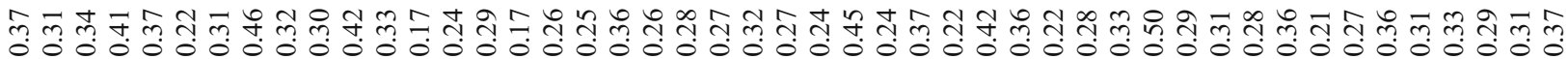

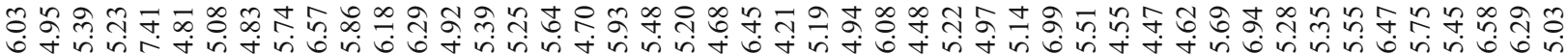

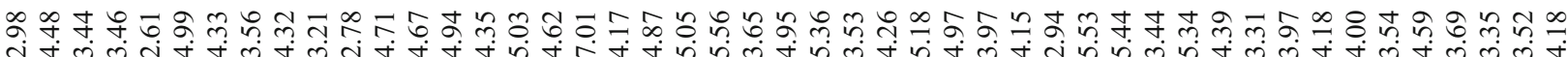

해유

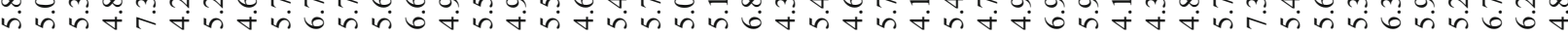

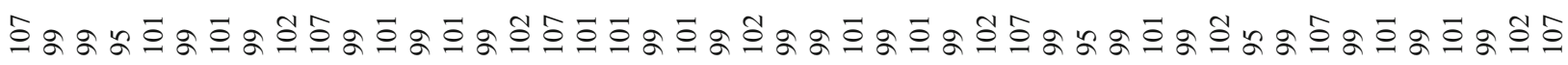

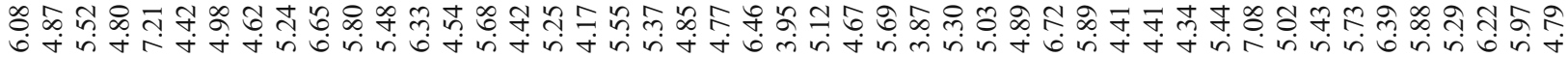

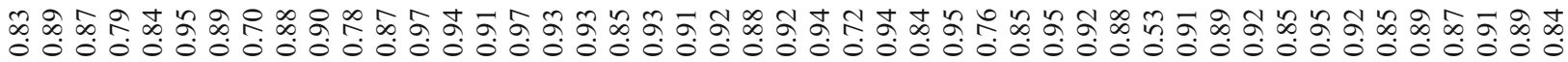


กิ त

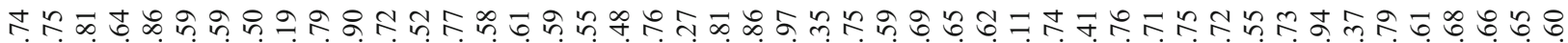

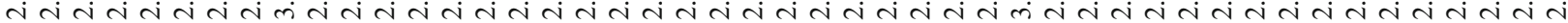

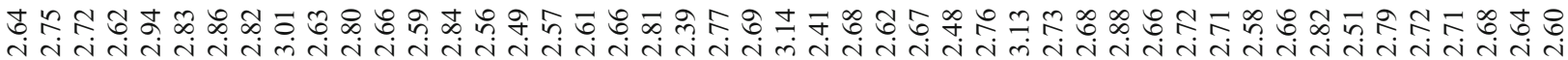

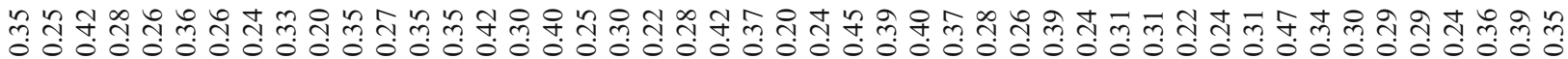

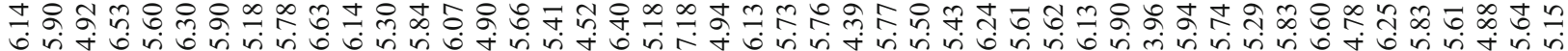

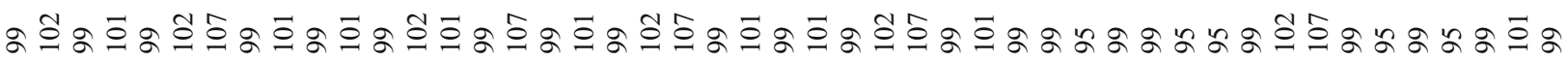

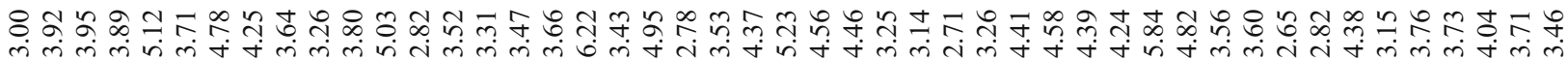

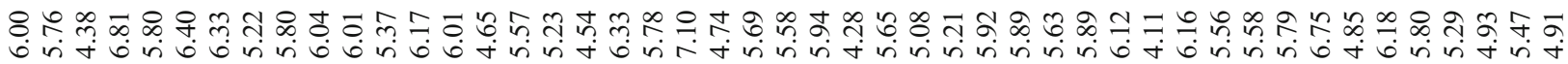

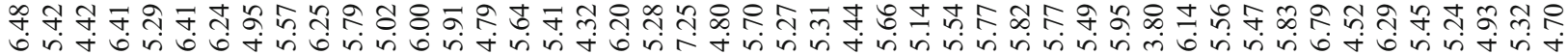

œ 
చธ융ำ u

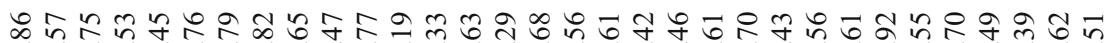

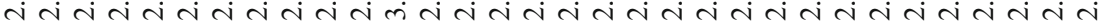

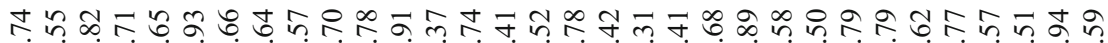

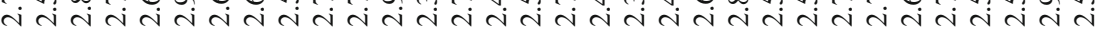

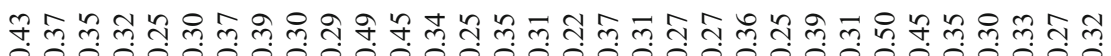

केㅊำ

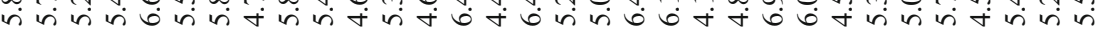

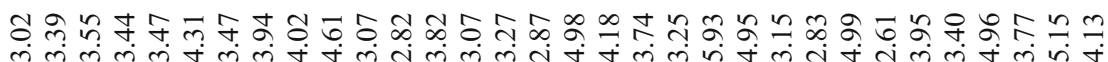

กำ

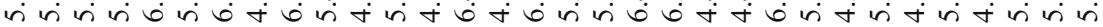

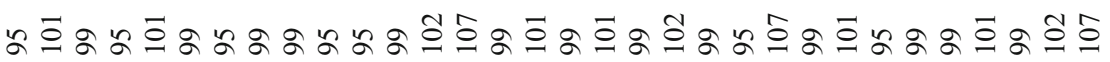

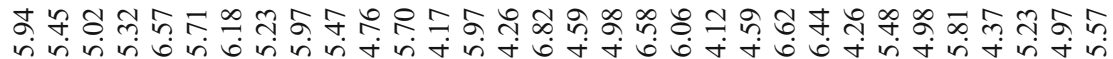

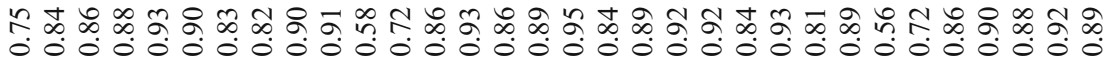

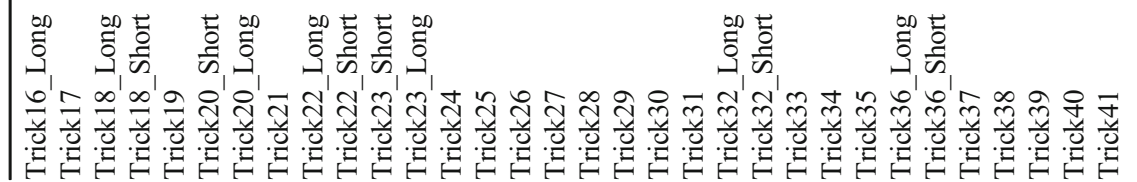




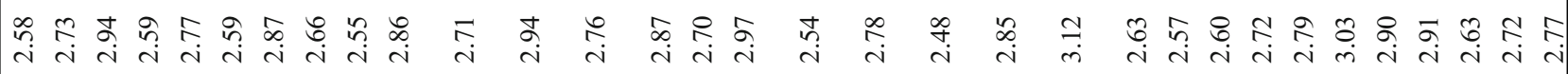

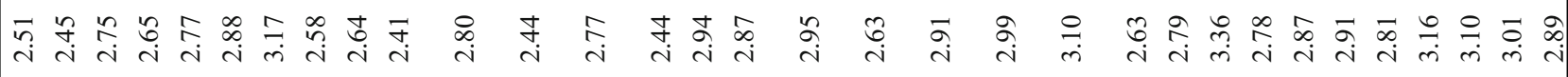

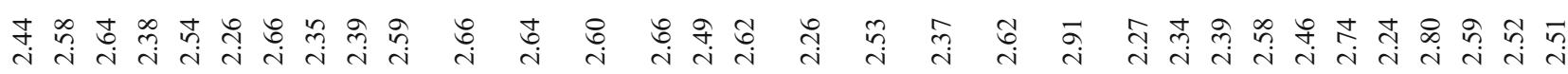

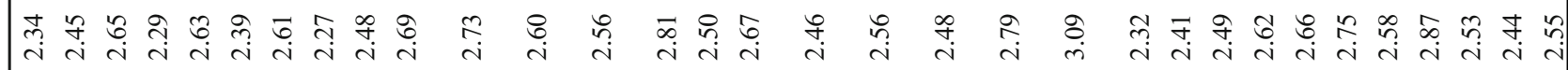

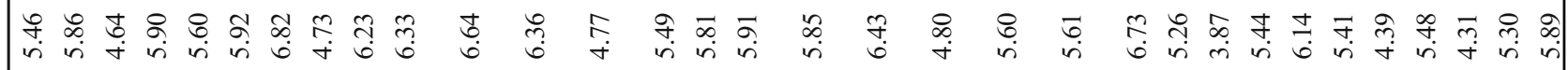

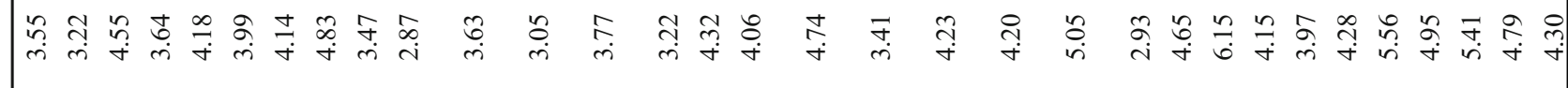

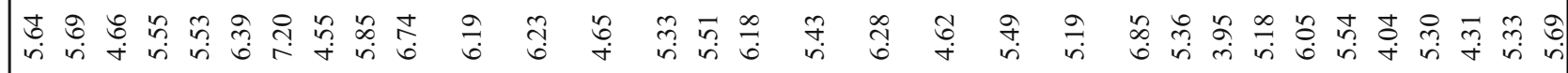

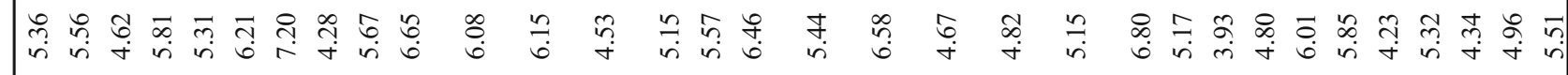

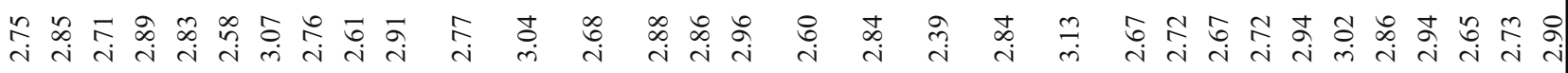

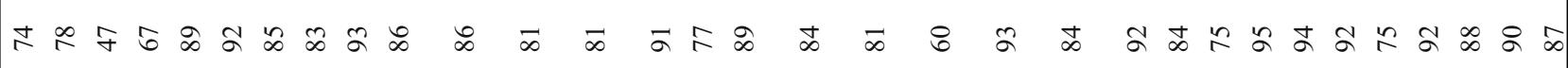

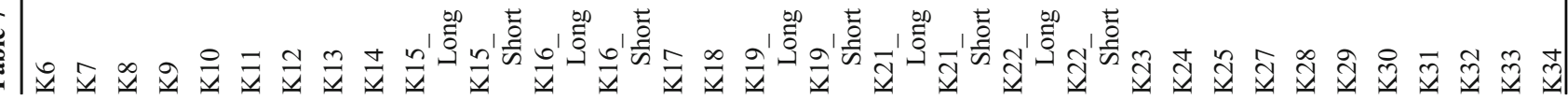




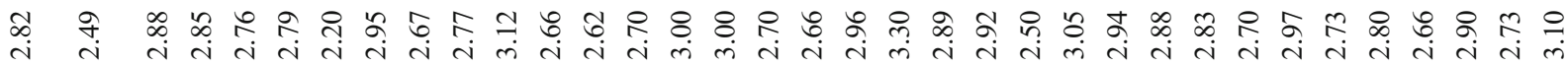

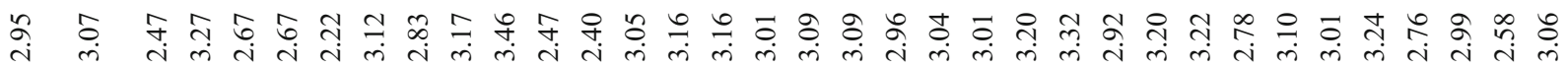

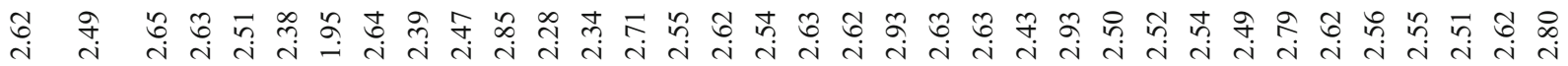

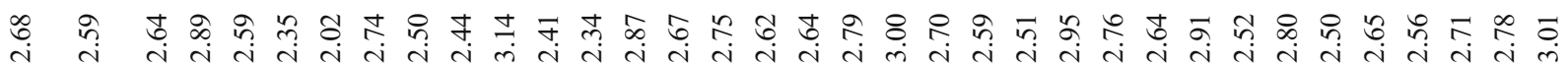

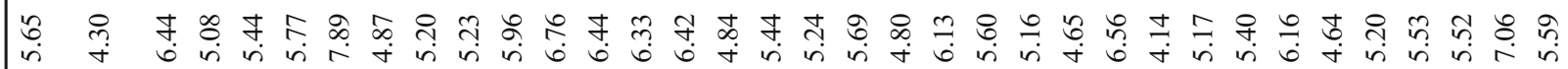

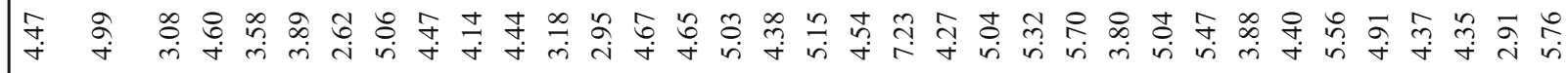

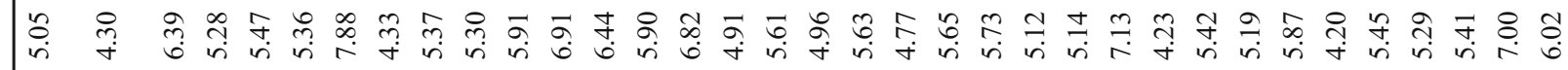

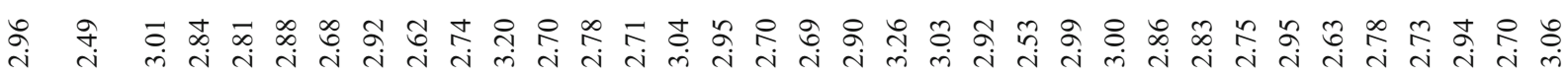

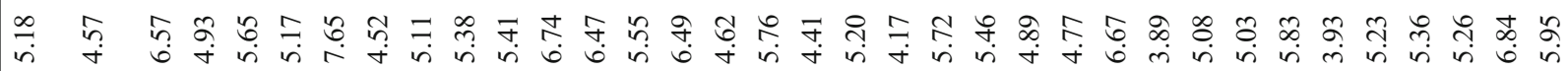

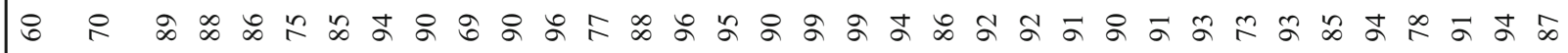
荥

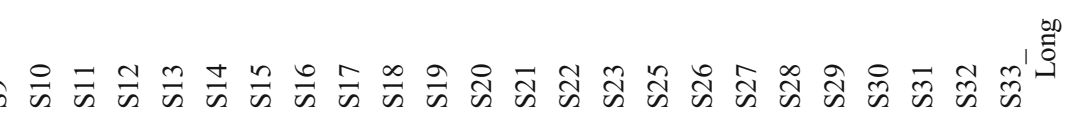




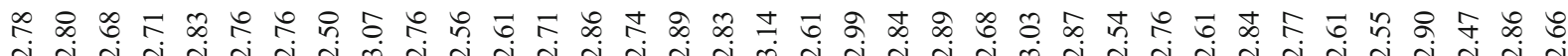

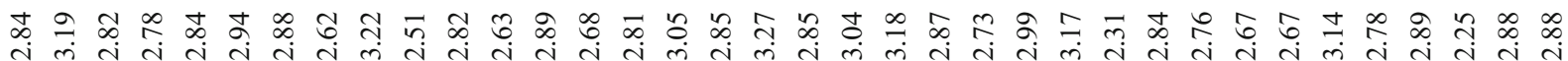

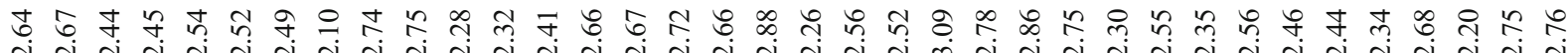

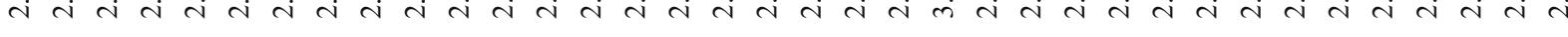

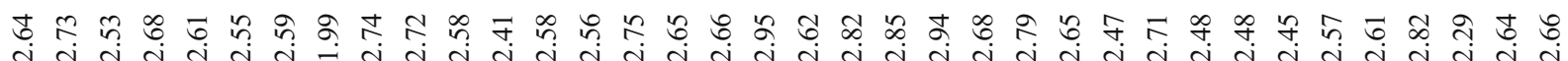

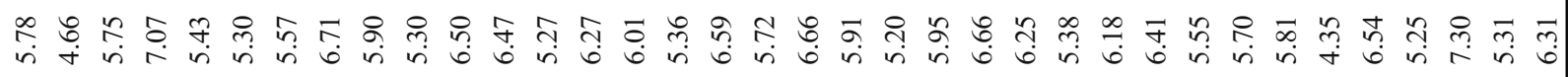

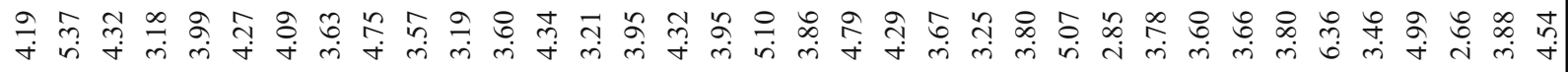

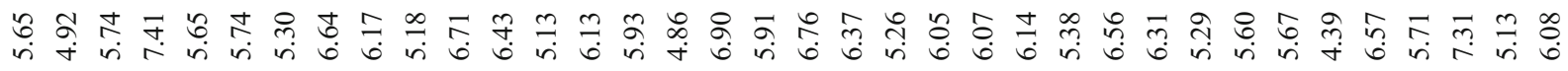

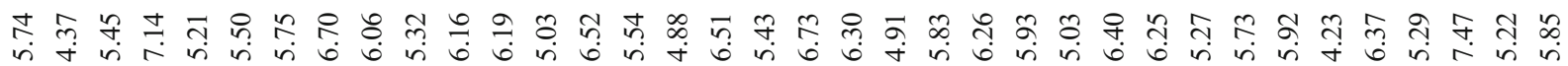
ஸ

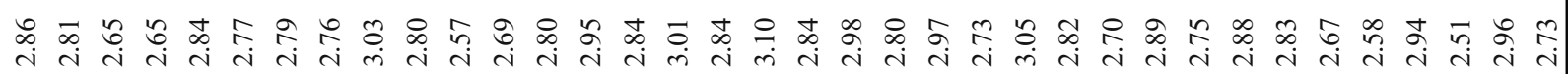

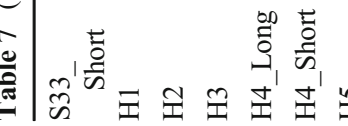




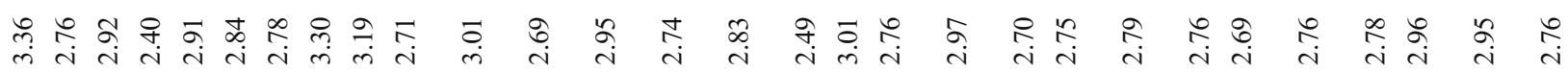

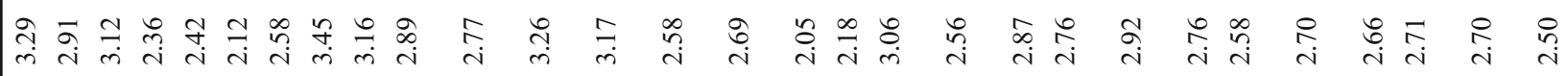

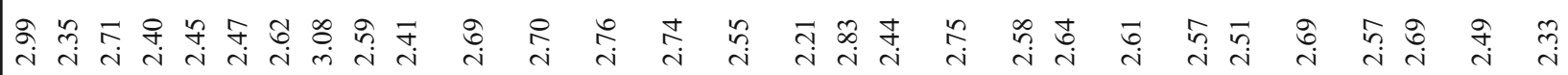

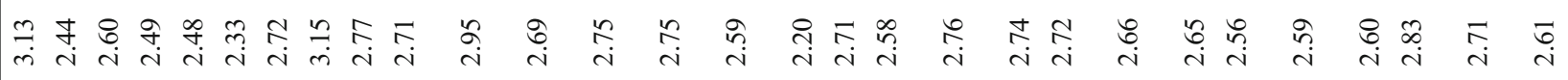

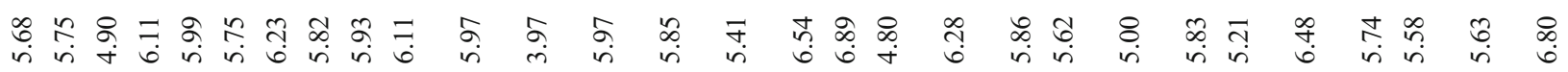

光

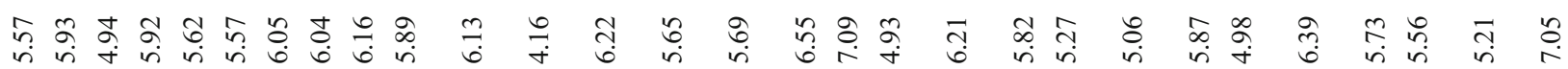

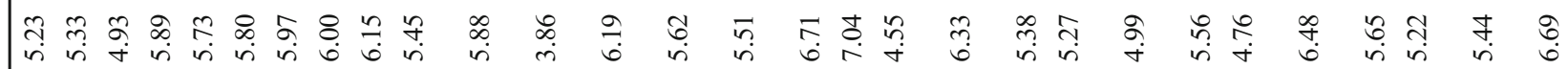

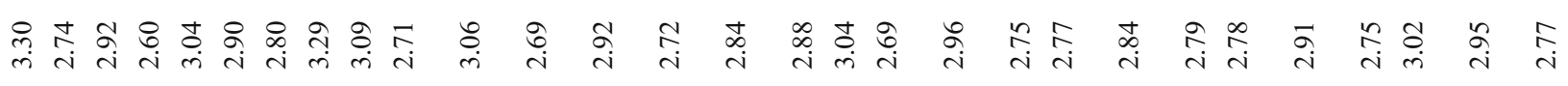

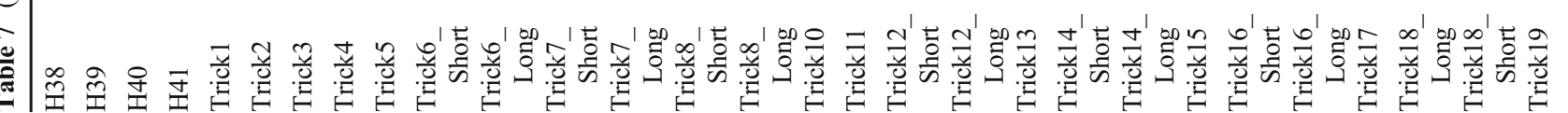




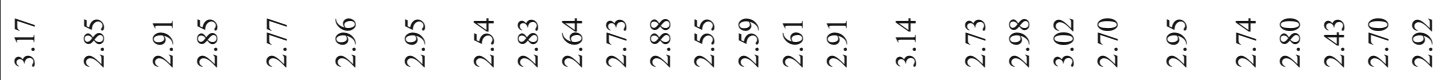

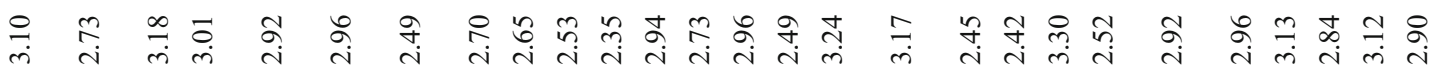

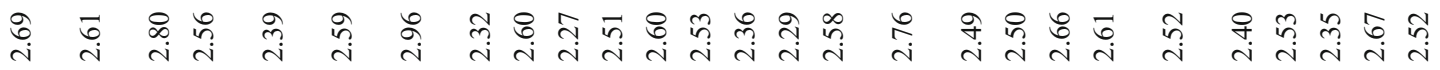

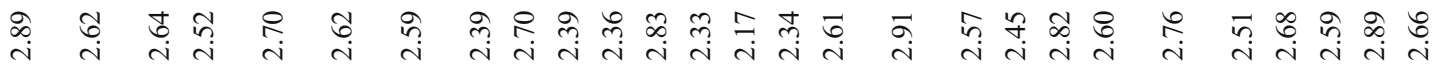

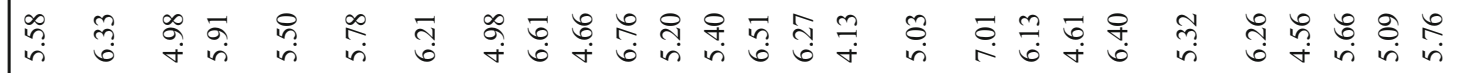

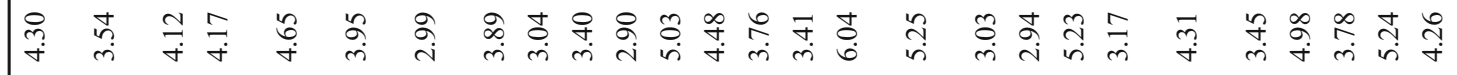

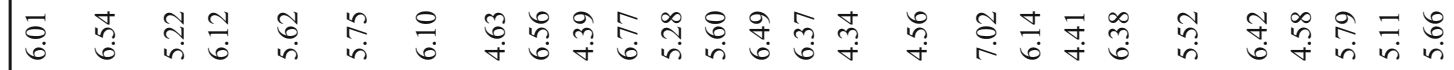

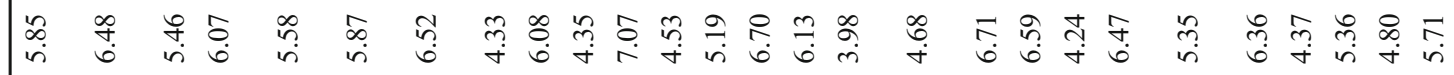

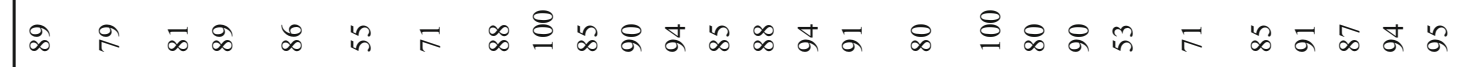

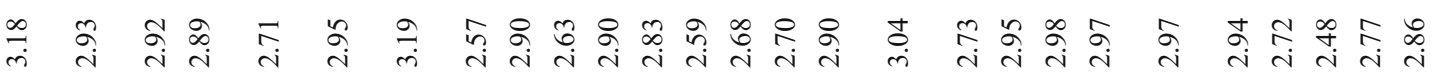

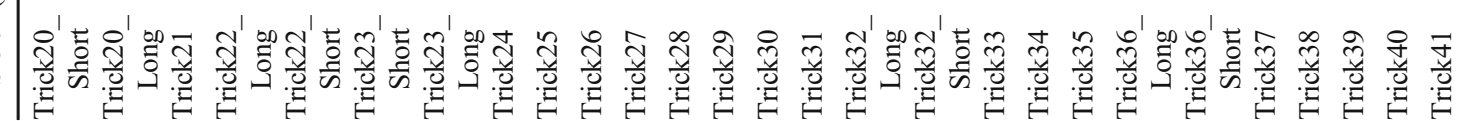


Table 8 Between-person correlations among ratings

$1 \quad 2 \quad 3$

1: surprise in response to the trick

2: interest in the trick

$0.91 *$

3: confidence in the solution

$-0.22 * * *-0.09 *$

4: curiosity in the solution

$0.84 * * *$

$0.89 * * *$

$-0.12 *$

$* p<.05, * * p<.01, * * * p<.001$

Open Access This article is licensed under a Creative Commons Attribution 4.0 International License, which permits use, sharing, adaptation, distribution and reproduction in any medium or format, as long as you give appropriate credit to the original author(s) and the source, provide a link to the Creative Commons licence, and indicate if changes were made. The images or other third party material in this article are included in the article's Creative Commons licence, unless indicated otherwise in a credit line to the material. If material is not included in the article's Creative Commons licence and your intended use is not permitted by statutory regulation or exceeds the permitted use, you will need to obtain permission directly from the copyright holder. To view a copy of this licence, visit http://creativecommons.org/licenses/by/4.0/.

\section{References}

Baranes, A., Oudeyer, P.-Y., \& Gottlieb, J. (2015). Eye movements reveal epistemic curiosity in human observers. Vision Research, 117, 81-90. https://doi.org/10.1016/j.visres.2015.10.009

Barnhart, A. S., \& Goldinger, S. D. (2014). Blinded by magic: Eye movements reveal the misdirection of attention. Frontiers in Psychology, 5, 1461. https://doi.org/10.3389/fpsyg.2014.01461

Brennan, R. L. (2001). Statistics for social science and public policy. Generalizability theory. Springer-Verlag Publishing. https://doi. org/10.1007/978-1-4757-3456-0

Brun, G., Doğuoğlu, U., \& Kuenzle, D. (Eds.). (2008). Epistemology and emotions. Aldershot, United Kingdom: Ashgate.

Danek, A. H., Öllinger, M., Fraps, T., Grothe, B., \& Flanagin, V. L. (2015). An fMRI investigation of expectation violation in magic tricks. Frontiers in psychology, 6, 84. https://doi.org/10.3389/ fpsyg.2015.00084

Diamantopoulos, A., Sarstedt, M., Fuchs, C., Wilczynski, P., \& Kaiser, S. (2012). Guidelines for choosing between multi-item and single-item scales for construct measurement: a predictive validity perspective. Journal of the Academy of Marketing Science, 40(3), 434-449. https://doi.org/10.1007/s11747-011-0300-3

Dole, J. A., \& Sinatra, G. M. (1998). Reconceptualizing change in the cognitive construction of knowledge. Educational Psychologist, 33(2-3), 109-128. https://doi.org/10.1207/s15326985ep3302\&3 5

Ekroll, V., Sayim, B., \& Wagemans, J. (2013). Against better knowledge: The magical force of amodal volume completion. i-Perception, 4(8), 511-515. https://doi.org/10.1068/10622sas

Fastrich, G. M., Kerr, T., Castel, A. D., \& Murayama, K. (2017). The role of interest in memory for trivia questions: An investigation with a large-scale database. Motivation Science, 4(3), 227-250. https://doi. org $/ 10.1037 / \operatorname{mot} 0000087$

Fayn, K., Silvia, P. J., Dejonckheere, E., Verdonck, S., \& Kuppens, P. (2019). Confused or curious? Openness/intellect predicts more positive interest-confusion relations. Journal of Personality and Social
Psychology, 117(5), 1016-1033. https://doi.org/10.1037/ pspp0000257

Fleiss, J. L. (1981). Balanced incomplete block designs for inter-rater reliability studies. Applied Psychological Measurement, 5(1), 105112. https://doi.org/10.1177/014662168100500115

Galli, G., Sirota, M., Gruber, M. J., Ivanof, B. E., Ganesh, J., Materassi, M., ... Craik, F. I. M. (2018). Learning facts during aging: the benefits of curiosity. Experimental Aging Research, 44(4), 311328. https://doi.org/10.1080/0361073X.2018.1477355

Gruber, M. J., Gelman, B. D., \& Ranganath, C. (2014). States of curiosity modulate hippocampus-dependent learning via the dopaminergic circuit. Neuron, 84(2), 486-496. https://doi.org/10.1016/j.neuron. 2014.08.060

Gygax, P., Thomas, C., Didierjean, A., \& Kuhn, G. (2019). Are Women Perceived as Worse Magicians Than Men? Social Psychological Bulletin, 14(3), 1-19. https://doi.org/10.32872/spb.v14i3.33574

Hanani, H. (1961). The existence and construction of balanced incomplete block designs. The Annals of Mathematical Statistics, 32(2), 361-386. https://doi.org/10.1214/aoms/1177705047

Hidi, S. E., \& Renninger, K. A. (2019). Interest Development and Its Relation to Curiosity: Needed Neuroscientific Research. Educational Psychology Review, 31(4), 833-852. https://doi.org/ 10.1007/s10648-019-09491-3

Jay, J. (2016). What do audiences really think. MAGIC(September), 46 55.

Jepma, M., Verdonschot, R. G., van Steenbergen, H., Rombouts, S., \& Nieuwenhuis, S. (2012). Neural mechanisms underlying the induction and relief of perceptual curiosity. Frontiers in Behavioral Neuroscience, 6, 5. https://doi.org/10.3389/fnbeh.2012.00005

Kang, M. J., Hsu, M., Krajbich, I. M., Loewenstein, G., McClure, S. M., Wang, J. T.-y., \& Camerer, C. F. (2009). The wick in the candle of learning: Epistemic curiosity activates reward circuitry and enhances memory. Psychological Science, 20(8), 963-973. https:// doi.org/10.1111/j.1467-9280.2009.02402.x

Kuhn, G. (2019). Experiencing the impossible: The science of magic. MIT Press.

Kuhn, G., Amlani, A. A., \& Rensink, R. A. (2008). Towards a science of magic. Trends in cognitive sciences, 12(9), 349-354. https://doi.org/ 10.1016/j.tics.2008.05.008

Kuhn, G., \& Findlay, J. M. (2010). Misdirection, attention and awareness: Inattentional blindness reveals temporal relationship between eye movements and visual awareness. Quarterly Journal of Experimental Psychology, 63(1), 136-146. https://doi.org/10.1080/ 17470210902846757

Kuhn, G., \& Land, M. F. (2006). There's more to magic than meets the eye. Current Biology, 16, R950-R951. https://doi.org/10.1016/j.cub. 2006.10 .012

Kuhn, G., Pailhès, A., \& Lan, Y. (2020). Forcing you to experience wonder: Unconsciously biasing people's choice through strategic physical positioning. Consciousness and Cognition, 80, 102902. https://doi.org/10.1016/j.concog.2020.102902

Lau, J. K. L., Ozono, H., Kuratomi, K., Komiya, A., \& Murayama, K. (2020). Shared striatal activity in decisions to satisfy curiosity and hunger at the risk of electric shocks. Nature Human Behaviour, 113. https://doi.org/10.1038/s41562-020-0848-3

Leddington, J. (2016). The experience of magic. The journal of aesthetics and art criticism, 74(3), 253-264. https://doi.org/10.1111/jaac. 12290

Litman, J., Hutchins, T., \& Russon, R. (2005). Epistemic curiosity, feeling-of-knowing, and exploratory behaviour. Cognition and Emotion, 19(4), 559-582. https://doi.org/10.1080/ 02699930441000427

Loewenstein, G. (1994). The psychology of curiosity: A review and reinterpretation. Psychological Bulletin, 116(1), 75-98. https://doi. org/10.1037/0033-2909.116.1.75 
Macknik, S. L., Martinez-Conde, S., \& Blakeslee, S. (2010). Sleights of mind: What the neuroscience of magic reveals about our everyday deceptions. NY: Henry Holt and Company.

Marvin, C. B., \& Shohamy, D. (2016). Curiosity and reward: Valence predicts choice and information prediction errors enhance learning. Journal of Experimental Psychology: General, 145(3), 266-272. https://doi.org/10.1037/xge0000140

McGillivray, S., Murayama, K., \& Castel, A. D. (2015). Thirst for knowledge: The effects of curiosity and interest on memory in younger and older adults. Psychology and Aging, 30(4), 835-841. https://doi. org/10.1037/a0039801

Metcalfe, J., Schwartz, B. L., \& Bloom, P. A. (2017). The tip-of-thetongue state and curiosity. Cognitive research: principles and implications, 2(1), 31-31. https://doi.org/10.1186/s41235-017-0065-4

Muis, K. R., Chevrier, M., \& Singh, C. A. (2018). The Role of Epistemic Emotions in Personal Epistemology and Self-Regulated Learning. Educational Psychologist, 53(3), 165-184. https://doi.org/10.1080/ 00461520.2017 .1421465

Murayama, K., Fitzgibbon, L., \& Sakaki, M. (2019). Process account of curiosity and interest: A reward learning framework of knowledge acquisition. Educational Psychology Review, 31(4), 875-895. https://doi.org/10.31219/osf.io/hbcz5.

Murayama, K., \& Kuhbandner, C. (2011). Money enhances memory consolidation-But only for boring material. Cognition, 119(1), 120-124. https://doi.org/10.1016/j.cognition.2011.01.001

Olson, J., Amlani, A., \& Rensink, R. (2013). Using magic to influence choice in the absence of visual awareness. Journal of Vision, 13(9), 1133-1133. https://doi.org/10.1167/13.9.1133

Ozono, H. (2017, September). What Kind of Magician's Choice is More Effective? An Experiment. Poster presented at the Science of Magic Association Conference, Goldsmiths, University of London.

Pailhès, A., \& Kuhn, G. (2020). Subtly encouraging more deliberate decisions: using a forcing technique and population stereotype to investigate free will. Psychological research. https://doi.org/10. 1007/s00426-020-01350-Z

Parris, B. A., Kuhn, G., Mizon, G. A., Benattayallah, A., \& Hodgson, T. L. (2009). Imaging the impossible: An fMRI study of impossible causal relationships in magic tricks. Neuroimage, 45(3), 1033-1039. https://doi.org/10.1016/j.neuroimage.2008.12.036

Pekrun, R., Vogl, E., Muis, K. R., \& Sinatra, G. M. (2017). Measuring emotions during epistemic activities: The Epistemically-Related Emotion Scales. Cognition and Emotion, 31(6), 1268-1276. https://doi.org/10.1080/02699931.2016.1204989

Podsakoff, P. M., MacKenzie, S. B., Lee, J.-Y., \& Podsakoff, N. P. (2003). Common method biases in behavioral research: A critical review of the literature and recommended remedies. Journal of Applied Psychology, 88(5), 879-903. https://doi.org/10.1037/ 0021-9010.88.5.879
Rescorla, R. A., \& Wagner, A. R. (1972). A theory of Pavlovian conditioning: Variations in the effectiveness of reinforcement and nonreinforcement. In A. H. Black \& W. F. Prokasy (Eds.), Classical conditioning II: Current research and theory (pp. 64 99). New York: Appleton-Century-Crofts.

Robinson, W.S. (1950). Ecological Correlations and the Behavior of Individuals. American Sociological Review. 15 (3): 351-357. https://doi.org/10.2307/2087176

Sakaki, M., Yagi, A., \& Murayama, K. (2018). Curiosity in old age: A possible key to achieving adaptive aging. Neuroscience \& Biobehavioral Reviews, 88, 106-116. https://doi.org/10.1016/j. neubiorev.2018.03.007

Shin, D. D., \& Kim, S. I. (2019). Homo Curious: Curious or Interested? Educational Psychology Review, 31(4), 853-874. https://doi.org/10. 1007/s10648-019-09497-x

Silvia, P. J. (2005). What Is Interesting? Exploring the Appraisal Structure of Interest. Emotion, 5(1), 89-102. https://doi.org/10. 1037/1528-3542.5.1.89

Stahl, A. E., \& Feigenson, L. (2015). Observing the unexpected enhances infants' learning and exploration. Science, 348(6230), 91-94. https:// doi.org/10.1126/science.aaa3799

Thomas, C., Didierjean, A., Maquestiaux, F., \& Gygax, P. (2015). Does magic offer a cryptozoology ground for psychology? Review of General Psychology, 19(2), 117-128. https://doi.org/10.1037/ gpr0000041

van Lieshout, L. L. F., Vandenbroucke, A. R. E., Müller, N. C. J., Cools, R., \& de Lange, F. P. (2018). Induction and relief of curiosity elicit parietal and frontal activity. The Journal of Neuroscience 38(10), 2579-2588. https://doi.org/10.1523/jneurosci.2816-17.2018

Vogl, E., Pekrun, R., Murayama, K., \& Loderer, K. (2019). Surprisedcurious-confused: Epistemic emotions and knowledge exploration. Emotion. https://doi.org/10.1037/emo0000578

Vogl, E., Pekrun, R., Murayama, K., Loderer, K., \& Schubert, S. (2019). Surprise, Curiosity, and Confusion Promote Knowledge Exploration: Evidence for Robust Effects of Epistemic Emotions. Frontiers in psychology, 10, 2474. https://doi.org/10.3389/fpsyg. 2019.02474

Wade, S., \& Kidd, C. (2019). The role of prior knowledge and curiosity in learning. Psychonomic Bulletin \& Review, 26(4), 1377-1387. https://doi.org/10.3758/s13423-019-01598-6

Wiseman, R. J., \& Nakano, T. (2016). Blink and you'll miss it: the role of blinking in the perception of magic tricks. PeerJ, 4, e1873. https:// doi.org/10.7717/peerj. 1873

Publisher's note Springer Nature remains neutral with regard to jurisdictional claims in published maps and institutional affiliations. 